\title{
Decadal trends in the Antarctic sea ice extent ultimately controlled by ice-ocean feedback
}

\author{
H. Goosse and V. Zunz \\ Université catholique de Louvain, Earth and Life Institute, Georges Lemaitre Centre for Earth and Climate Research, \\ Place Pasteur, 3, 1348 Louvain-la-Neuve, Belgium
}

Correspondence to: H. Goosse (hugues.goosse@uclouvain.be)

Received: 27 August 2013 - Published in The Cryosphere Discuss.: 11 September 2013

Revised: 4 February 2014 - Accepted: 10 February 2014 - Published: 18 March 2014

\begin{abstract}
The large natural variability of the Antarctic sea ice is a key characteristic of the system that might be responsible for the small positive trend in sea ice extent observed since 1979. In order to gain insight of the processes responsible for this variability, we have analysed in a control simulation performed with a coupled climate model a positive ice-ocean feedback that amplifies sea ice variations. When sea ice concentration increases in a region, in particular close to the ice edge, the mixed layer depth tends to decrease. This can be caused by a net inflow of ice, and thus of freshwater, that stabilizes the water column. A second stabilizing mechanism at interannual timescales is associated with the downward salt transport due to the seasonal cycle of ice formation: brine is released in winter and mixed over a deep layer while the freshwater flux caused by ice melting is included in a shallow layer, resulting in a net vertical transport of salt. Because of this stronger stratification due to the presence of sea ice, more heat is stored at depth in the ocean and the vertical oceanic heat flux is reduced, which contributes to maintaining a higher ice extent. This positive feedback is not associated with a particular spatial pattern. Consequently, the spatial distribution of the trend in ice concentration is largely imposed by the wind changes that can provide the initial perturbation. A positive freshwater flux could alternatively be the initial trigger but the amplitude of the final response of the sea ice extent is finally set up by the amplification related to the ice-ocean feedback. Initial conditions also have an influence as the chance to have a large increase in ice extent is higher if starting from a state characterized by a low value.
\end{abstract}

\section{Introduction}

In contrast to the Arctic where a strong decrease has been observed, particularly in summer, sea ice extent has slightly increased over the last decades in the Southern Ocean (Comiso and Nishio, 2008; Cavalieri and Parkinson, 2012; Parkinson and Cavalieri, 2012). For the period November 1978-December 2010, satellite observations indicate a significant positive sea ice extent trend of $1.7 \times 10^{5} \pm 2 \times$ $10^{4} \mathrm{~km}^{2}$ per decade (Cavalieri and Parkinson, 2012). A positive trend is also noticed for every month, with a minimum in February at a value a bit lower than $10^{5} \mathrm{~km}^{2}$ per decade (Cavalieri and Parkinson, 2012).

The causes of this positive trend in a generally warming world are still debated. The regional distribution of the changes, characterized by a maximum increase in ice extent in the Ross Sea and a decrease in the Bellingshausen Sea (Parkinson and Cavalieri, 2012), is mainly driven by the winds but their effect on the total ice extent is less clear (e.g. Liu et al., 2004; Lefebvre et al., 2004; Goosse et al., 2009; Holland and Kwok, 2012; Simpkins et al., 2012). Modifications in the hydrological cycle of the Southern Ocean could contribute to the observed positive trend (e.g. Liu and Curry, 2010; Bintanja et al., 2013): higher snowfalls induce a higher albedo as well as snow ice formation leading to an increase in ice thickness; larger precipitation rates lead to a lower sea surface salinity, a stronger oceanic stratification, and a reduction in the vertical oceanic heat transport that favours ice formation (e.g. Martinson, 1990; Fichefet and Morales Maqueda, 1999; Marsland and Wolff, 2001). Enhanced melting of the Antarctic ice sheet, in particular of the ice shelves, also induces a freshwater transport towards the ocean, which 
could lead to a decrease in surface salinity and an increase in sea ice extent in a similar way as increased precipitation (e.g. Jacobs et al., 2002; Swingedouw et al., 2008; Bintanja et al., 2013; Swart and Fyfe, 2013).

In response to natural and anthropogenic forcings, climate models simulate a weak decrease of the ice extent over the past decade (e.g. Lefebvre and Goosse, 2008a; Turner et al., 2013; Zunz et al., 2013; Mahlstein et al., 2013). The disagreement with the observed increase might be due to the misrepresentation in models of some important feedbacks, related for instance to changes in wind patterns or in the freshwater cycle in a warmer world, as well as to the absence of a net meltwater input from the Antarctic ice sheet in the large majority of the global climate models (e.g. Liu and Curry, 2010; Bintanja et al., 2013; Mahlstein et al., 2013; Swart and Fyfe, 2013). Alternatively, the observed positive trend of sea ice extent might be the manifestation of the large internal variability of the climate system in the Southern Ocean that would overwhelm the effect of the forcing associated with a weak decrease of the ice extent. Unfortunately, time series of observed ice extent are too short in the Southern Ocean to precisely quantify the magnitude of its multidecadal variability. Additionally, a few models display an increase in ice extent when both the response to the forcing and the internal variability of the system are taken into account. A dominant role of the internal variability in the recent changes in sea ice in the Southern Ocean is thus marginally compatible with simulated results, but models have clear biases in their representation of both the mean state and the variability of the sea ice there, making the validity of this hypothesis relatively uncertain (Zunz et al., 2013; Mahlstein et al., 2013; Swart and Fyfe, 2013; Polvani and Smith, 2013).

Numerous studies have been devoted to the interannual variability of the sea ice in the Southern Ocean, describing in detail the response of the system to the dominant modes of atmospheric variability (e.g. Stössel and Kim, 1998; Timmermann et al., 2002; Liu et al., 2004; Lefebvre et al., 2004; Holland and Raphael, 2006; Zhang, 2007; Yuan and Li, 2008; Simpkins et al., 2012). The multicentennial variability has also been investigated, focusing on the causes and on the large-scale impact of changes in deep convection and deep water formation in the Southern Ocean (e.g. Mikolajewicz and Maier-Reimer, 1990; Santoso and England, 2008; Martin et al., 2013). Furthermore, although several recent studies have quantified the simulated internal variability in the framework of analyses of the changes over the last decades (e.g. Zunz et al., 2013; Mahlstein et al., 2013; Swart and Fyfe, 2013; Polvani and Smith, 2013), only a few analyses have explicitly looked at mechanisms responsible for variability at multidecadal timescales (e.g. Beckmann and Timmermann, 2001; Stöessel and Kim, 2001).

Our goal here is thus to specifically analyse those mechanisms that could lead to an increase in ice extent similar to the one observed over the last 30 years. We will particularly focus on ice-ocean interactions because of their large role in the Southern Ocean dynamics (e.g. Gordon, 1981; Martinson, 1990; Goosse and Fichefet, 1999; Bitz et al., 2006; Zhang, 2007; Goosse et al., 2009; Kirkman and Bitz, 2010). This will be achieved by describing first the dominant processes in a long control simulation (i.e. using constant forcing) performed with a coupled climate model. In a second step, we will determine how those processes contribute to the trend simulated over the last decades in a simulation obtained with the same model constrained to follow the observed changes using data assimilation. The model and the data assimilation technique are briefly presented in Sect. 2 . Section 3 is devoted to the analysis of the multidecadal variability of the control simulation. A simple model is used in Sect. 4 to illustrate the potential stabilization of the water column associated with sea ice formation. Section 5 is focussed on the recent changes in the simulation with data assimilation. Finally, conclusions are given in Sect. 6.

\section{Methodology}

\subsection{Model description}

The model used here is LOVECLIM (LOch-Vecode-EcbiltCLio-agIsm Model; Goosse et al., 2010), a coupled climate model of intermediate complexity. Its atmospheric component is ECBilt2 (Opsteegh et al., 1998), a quasi-geostrophic model with $\mathrm{T} 21$ horizontal resolution (corresponding to about $5.6^{\circ}$ by $5.6^{\circ}$ ). CLIO, the ocean component (Goosse and Fichefet, 1999), is a general circulation model with a horizontal resolution of $3^{\circ}$ by $3^{\circ}$. A simple vegetation model (VECODE, Brovkin et al., 2002) is also activated in the configuration selected here, at the same resolution as in ECBilt.

LOVECLIM has a coarser resolution than the state-of-theart coupled general circulation models (CGCMs) and has a simplified representation of atmospheric dynamics. Nevertheless, its ocean component is a general circulation model and its sea ice model is nearly identical to LIM2 (Louvainla-Neuve sea-Ice model, version 2, Fichefet and Morales Maqueda, 1997), which is included in some models (e.g. Hazeleger et al., 2010; Dufresne et al., 2013) used in CMIP5 (Coupled Model Intercomparison Project, Phase 5). It simulates a seasonal cycle of the sea ice extent well in the range of the one of the CGCMs (see Supplement, Fig. S1). Furthermore, because of its lower computational requirements, it is possible to make long spin-ups with the model until it reaches an equilibrium and thus to avoid the trouble associated with long-term drift in the Southern Ocean seen in some more sophisticated models (Sen Gupta et al., 2009, 2012; Turner et al., 2013). Finally, the model is well adapted for data assimilation using ensemble techniques and we can thus easily compare long control simulations with experiments reproducing the recent changes thanks to the data constraint (see below). 
LOVECLIM is thus an interesting tool to study the natural variability of the ice extent on multidecadal timescales. It is well known that different models can behave quite differently in the Southern Ocean (Sen Gupta et al., 2009; Turner et al., 2013; Zunz et al., 2013; Close and Goosse, 2013). However, our goal is not to estimate quantitatively the different processes or to evaluate the skill of models in the Southern Ocean but to describe important feedbacks. It is thus easier if we base our analysis on one single model for which all the required diagnostics are available (which is generally not the case in public archives for long control runs). Nevertheless, we should ensure that our conclusions are robust and not model dependent if we want to improve our understanding of the recent changes in ice extent. To do so, the results of LOVECLIM will be briefly compared to the ones from CGCMs when discussing the trend over the last 30 years.

\subsection{Data assimilation method}

The data assimilation method is based on a particle filter (e.g. van Leeuwen, 2009) using the implementation described in Dubinkina et al. (2011) and Dubinkina and Goosse (2013). Ninety-six members (called "particles") are propagated in time by the climate model, starting from an ensemble initialized in the year 1850. A nudging term is included to bring the surface temperature in ice free areas close to the observed one (Brohan et al., 2006), using a restoring timescale equivalent to 20 days for a depth of $50 \mathrm{~m}$. Every 3 months, the likelihood of each particle is then estimated as a function of the difference between the simulated temperatures and the HadCRUT3 surface air temperatures over the domain $30^{\circ}-$ $90^{\circ} \mathrm{S}$ (Brohan et al., 2006), taking into account the information already brought by the nudging, as explained in Dubinkina and Goosse (2013). The particles are then resampled according to their likelihood, i.e. to their ability to reproduce the signal derived from the observations. The particles with low likelihood are stopped, while the particles with a high likelihood are copied a number of times proportional to their likelihood in order to keep the total number of particles constant throughout the period covered by the simulations. A small noise is added to each copy to obtain different time developments for the following period. The entire procedure is repeated sequentially until the end of the period of interest.

\section{Mechanism leading to large 30 year trends in sea ice extent in a control experiment}

\subsection{Changes observed during the periods of large increase in sea ice extent}

A 5000 year simulation has been performed with LOVECLIM, using constant forcing corresponding to pre-industrial conditions. The last 1000 years of this experiment display a stable climate with, for instance, a trend of the global mean depth-integrated ocean temperature smaller than $0.01^{\circ} \mathrm{C}$ per

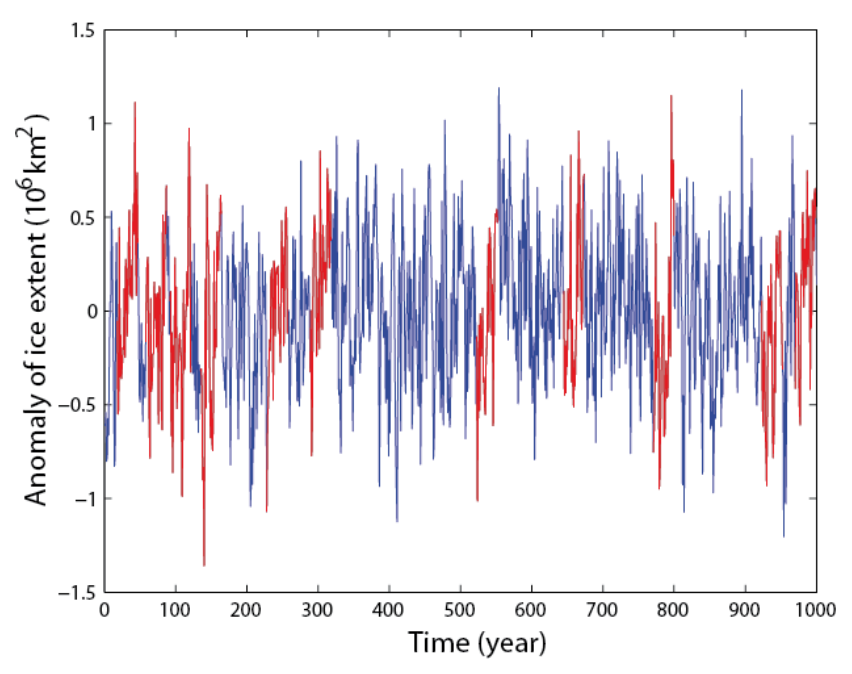

Fig. 1. Time series of the anomaly of annual mean sea ice extent in a long control run performed with LOVECLIM with regard to the mean over the full period investigated. The 11 periods characterized by an increase, at a rate larger than $10^{5} \mathrm{~km}^{2}$ per decade during 30 years, in each month of the year are in red.

century, i.e. of the same order as the internal variability of this variable in the model. This period is analysed in order to describe the internal processes that can lead to a multidecadal trend in ice extent in LOVECLIM. To do so, we have identified in those 1000 simulated years 11 periods for which the ice extent is increasing at a rate of at least $10^{5} \mathrm{~km}^{2}$ per decade for each calendar month, during a minimum of 30 years (Fig. 1). This value has been selected as it roughly corresponds to the increase observed over the period 19792010 analysed by Cavalieri and Parkinson (2012). Those 11 periods are scattered during the millennium analysed with, for instance, four of them in the first 150 years and none between years 300 and 500. They also have different characteristics as some display a relatively steady increase while the others have a much more variable time development.

As expected, during the periods of large positive trends in ice extent, on average, ice concentration tends to increase in all the sectors of the Southern Ocean (Fig. 2a). This corresponds to a cooling of the air near the surface that reaches more than $1 \mathrm{~K}$ in annual mean close to the ice edge (Fig. 2b) and a decrease in the heat content of the surface layer defined here as the top $100 \mathrm{~m}$ of the water column (Fig. 2c). The strong link between those variables is confirmed by the high correlation $(-0.71)$ between the spatial distribution of the trend of ice concentration and heat content displayed in Fig. 2a and c (Table 1). The ice also tends to become thicker, on average, during those periods in the majority of the regions (Fig. 2d) except in the southern part of the Weddell Sea, but the signal is not significant there. Furthermore, as the thickening is larger in regions inside the pack where changes in concentration are lower, the spatial correlation between the 

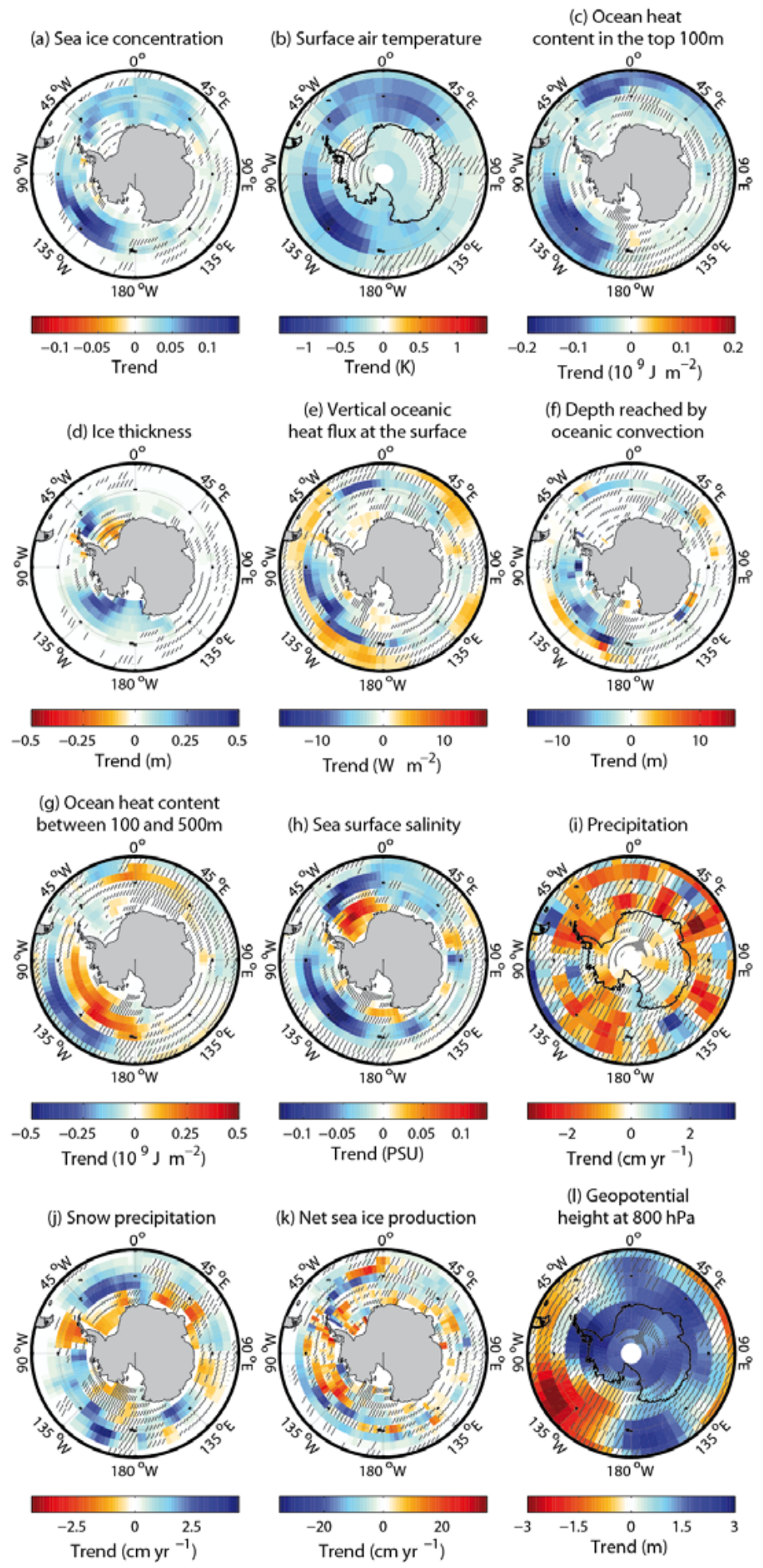

Fig. 2. Trends in annual means averaged over the 11 periods showing a large increase in Antarctic sea ice extent scaled to represent 30 year changes of (a) ice concentration, (b) surface air temperature (K), (c) ocean heat content in the top $100 \mathrm{~m}\left(\mathrm{~J} \mathrm{~m}^{-2}\right),(\mathbf{d})$ ice thickness (m), (e) vertical oceanic heat flux at the ocean surface (positive upward, $\mathrm{W} \mathrm{m}^{-2}$ ), (f) depth reached by oceanic convection (m), (g) ocean heat content in the layer between 100 and $500 \mathrm{~m}\left(\mathrm{~J} \mathrm{~m}^{-2}\right)$, (h) sea surface salinity, (i) total precipitation $\left(\mathrm{cm} \mathrm{year}^{-1}\right)$, (j) snow precipitation (cm year ${ }^{-1}$ water equivalent), (k) net sea ice production (production minus melting) ( $\mathrm{cm}_{\text {year }}{ }^{-1}$ water equivalent), and (l) geopotential height at $800 \mathrm{hpa}(\mathrm{m})$. The hatched areas represent the regions for which the average trend over the 11 periods is not significantly different at the $95 \%$ level from the mean trend in periods of identical length but not showing a large increase in ice extent. 
trends in ice thickness and ice concentration is relatively low (0.36).

Despite the cooling of the air near the surface, the vertical oceanic heat flux at the surface (i.e. the upward flux at the ocean-atmosphere or ocean-ice interface, Fig. 2e) strongly decreases in ice covered regions, with changes of more than $15 \mathrm{~W} \mathrm{~m}^{-2}$ in annual mean. The spatial correlation between the trend in ice concentration and in heat flux at the ocean surface reaches -0.72 . Additionally, off the ice edge, where the insulating barrier associated with sea ice is not present, the oceanic heat losses increase. The presence of sea ice, which limits the exchanges between the ocean and the cold atmosphere, is not the only cause of the different behaviour between ice-covered and ice free regions. The depth reached by convection is also contrasted between those regions. On the one hand, the mixed layer becomes deeper in some icefree areas such as around $135^{\circ} \mathrm{W}$ because of the surface cooling that induces higher surface densities. On the other hand, it becomes generally shallower at higher latitudes, particularly in the Pacific sector where the largest changes in ice concentration are found on average (Fig. 2f). Consequently, the entrainment of the relatively warm water at depth into the mixed layer decreases at high latitudes, the heat content of the water column below $100 \mathrm{~m}$ (a depth which is close to the mean simulated winter mixed layer depth in the open ocean) becomes higher (Fig. 2g) and the vertical oceanic heat flux is reduced, contributing to maintaining the ice at the surface. The spatial correlation between the trend of heat content at depth and the one of ice concentration is lower than between ice concentration and some other surface variables, as temperature in intermediate layers is influenced by many processes, but it still reaches 0.42 on average.

The increase in the ice extent and the decrease in the depth reached by convection are associated with a surface freshening in many ice covered regions, except close to the continent in the Weddell and Ross seas and around $80^{\circ} \mathrm{E}$ where the salinity tends to increase (Fig. 2h). If this salinity decrease is caused by modifications of the fluxes at the ocean surface, it could be one of the origins of the shallower mixed layer because of the decrease in surface density it induces. Alternatively, this reduced salinity could be a consequence of the changes in mixing as the entrainment at the basis of the mixed layer brings relatively salty water masses to the surface layer and any reduction of its intensity (Fig. 2f) leads to a decrease of the salinity there.

Precipitation slightly decreases in periods of large increase in ice extent (Fig. 2i), likely because of the general cooling at high latitudes. This would tend to increase the surface salinity and precipitation changes could thus not explain the simulated freshening. This effect is, however, small and not significant in the majority of the regions. Note that, despite this reduction, a larger proportion of precipitation is falling in form of snow in colder conditions. This leads to an increase in snow precipitation in some regions close to the winter ice edge, while in some other areas, such as the Weddell Sea, the decrease in total precipitation implies a decrease in snowfall too (Fig. 2j). Consequently, the trend in precipitation produces a small negative feedback on the increase in sea ice extent in our experiments as it tends to destabilize the water column. Moreover, snow may contribute to a weak positive feedback in some regions by bringing additional mass to the snow-sea ice system, in particular through snow ice formation (e.g. Fichefet and Morales Maqueda, 1999).

On average, when the trend in ice extent is positive, the local net ice production integrated over one full year increases inside the pack while it decreases close to the ice edge (Fig. 2k). This net ice production is the result of local production and local melting. In the seasonal ice zone, as all the ice present during the year melts in summer, any imbalance between those two quantities is due to ice transport convergence or divergence. Therefore, the positive trend in many regions inside the pack is due to the colder air and lower oceanic heat flux that cause less ice melting and more ice formation, resulting in a net northward export of sea ice. Close to the ice edge, it leads to a decrease in the net ice production due to the larger transport towards this region in colder conditions. The correlation between the trend in ice concentration and the one in net ice formation is, however, very close to zero. This is due to the fact that, in some areas, a higher local ice formation leads, as expected at first sight, to a higher ice concentration. In some regions that are already ice covered a higher formation is associated with higher ice thickness but no change in ice concentration. Close to the ice edge, net ice formation is negative (i.e. more melting as ice is mainly present there because of the transport from southern latitudes), while ice concentration increases. Overall, the correlation between the two fields is thus very low.

These changes in local ice formation and melting (and thus in transport) contribute to the decrease in salinity, the shallower mixed layer depth and the reduced vertical heat fluxes close to the ice edge (Fig. 3a); and are also responsible for the higher surface salinities in some areas close to the continent. Nevertheless, the spatial distribution of the trends in net ice production, surface salinity and depth reached by convection displays clear differences. At many locations, lower sea surface salinities and a shallower mixed layer are associated with higher net ice production. This leads to a very low correlation between the spatial distribution of the trend in ice production and the depth reached by convection (0.06). More generally, the correlation between the total freshwater flux at the ocean surface (which includes the contribution of ice melting/freezing) and the depth reached by convection is also very low (0.07).

Although the sea ice transport plays an obvious role in the expansion of the pack, the stabilization of the water column in many areas is thus not due to a net inflow of ice that melts locally, leading to a higher annual mean freshwater flux at the ocean surface. This must be attributed to other processes. If sea ice is formed during a particular year, the brine is released in winter when the mixed layer is deep and contributes 
Table 1. Correlation between ice concentration trend and other model variables.

\begin{tabular}{|c|c|c|}
\hline & $\begin{array}{l}\text { Correlation for the } \\
\text { mean over the } 11 \text { periods }\end{array}$ & $\begin{array}{r}\text { Mean correlation for } \\
\text { all the } 11 \text { periods }\end{array}$ \\
\hline Oceanic heat content in the top $100 \mathrm{~m}$ & -0.71 & -0.63 \\
\hline Oceanic heat content between 100 and $500 \mathrm{~m}$ & 0.42 & 0.10 \\
\hline Ice thickness & 0.36 & 0.35 \\
\hline Heat flux at the ocean surface & -0.72 & -0.49 \\
\hline Depth reached by convection & -0.52 & -0.30 \\
\hline Sea surface salinity & -0.66 & -0.44 \\
\hline Net ice production & 0.002 & -0.08 \\
\hline Net freshwater flux at the ocean surface & 0.10 & 0.12 \\
\hline Snow precipitation & 0.37 & 0.11 \\
\hline
\end{tabular}

Correlation between the 30 year trends in ice concentration at each grid point that is ice covered and the trend in several variables at the same location during the periods of large increase in ice extent. The first column represents the correlation applied on the average over the 11 periods while for the second column all the periods are considered individually in the analysis.

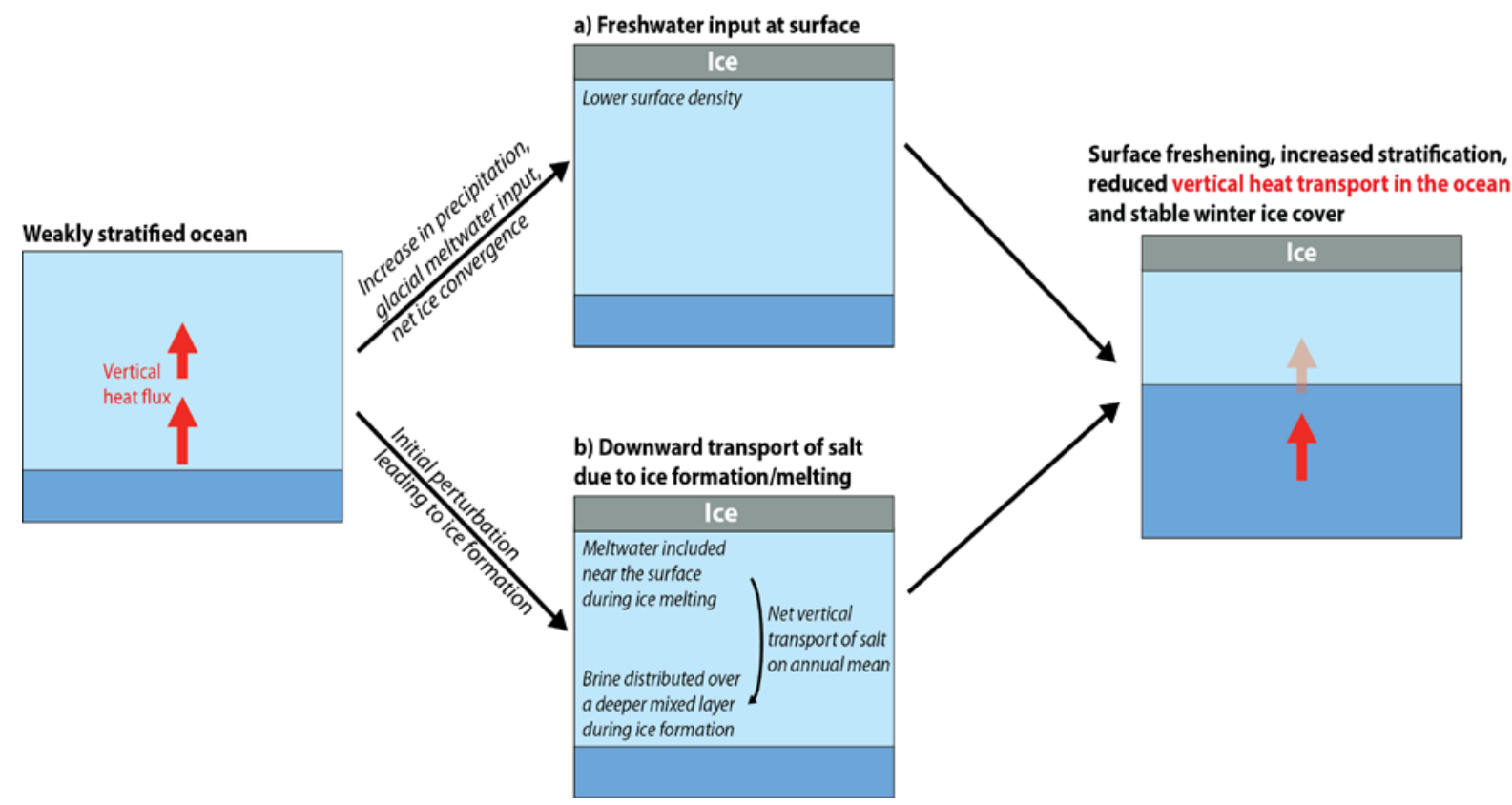

Fig. 3. Schematic representation of the stabilization of the Southern Ocean by sea ice processes.

to the mixed layer deepening. Consequently, the salt input is distributed over a relatively large depth. If the mixed layer depth was constant during the whole year and in the absence of sea ice transport, the sea ice melting in summer will perfectly compensate for this brine release and no net effect on the ocean salinity would be observed in the annual mean. This is not the case as the mixed layer is shallower in summer when sea ice is melting. The freshwater is thus incorporated only in the top layers of the ocean (Fig. 3b). While in this example the ice melting in summer is identical to the ice formation in winter, resulting in a zero mean freshwater flux, the consequence in the annual mean is a net downward transport of salt. This is ultimately responsible for the deep water formation in the Southern Ocean (e.g. Gordon 1991), a decrease of the potential energy of the water column and a strong stratification in summer that preconditions the water column for reduced mixed layer depths in subsequent seasons. As we consider that this mechanism deserves specific attention, we will further investigate it using a simple model in Sect. 4.

\subsection{Differences between the mean and the individual periods, focussing on the role of the atmospheric circulation}

As a large number of studies have advocated for a dominant role of the atmospheric circulation in the changes in sea ice concentration, it might be surprising that the trend in geopotential height on average for the 11 periods is very low in 

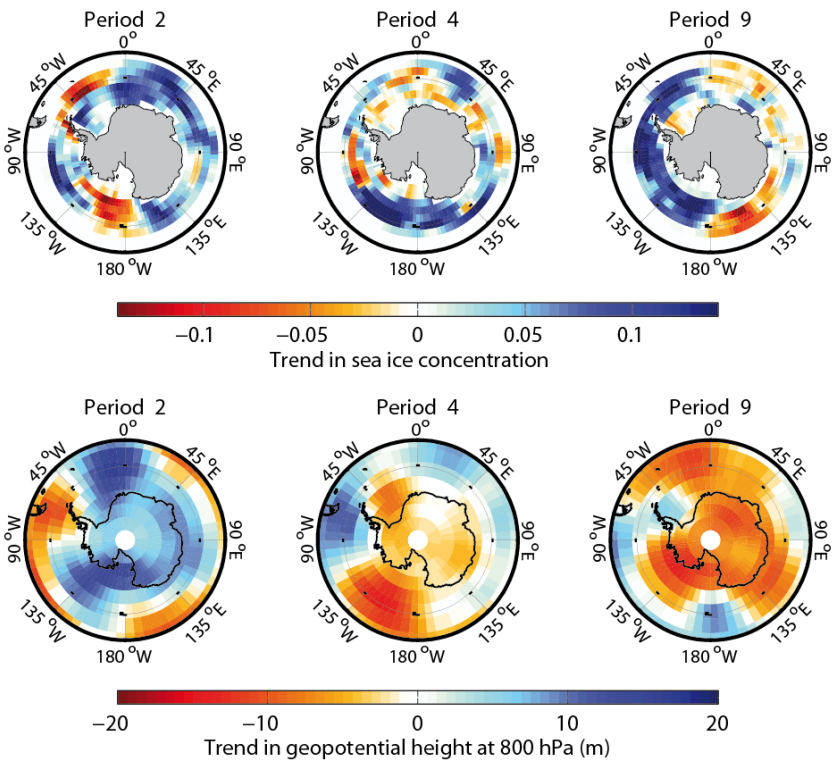

Fig. 4. Trends in annual mean ice concentration (top row) and in geopotential height at $800 \mathrm{hpa} \mathrm{(m)} \mathrm{(bottom} \mathrm{row)} \mathrm{for} \mathrm{the} 3$ selected periods among the 11 ones showing a large increase in Antarctic sea ice extent, scaled to represent 30 year changes. The 11 corresponding figures for all the 11 periods are provided as supplementary material.

our simulations and not significant in many regions (Fig. 21). This is due to the fact that the spatial patterns of geopotential trends are very different in the 11 periods during which sea ice extent strongly increases (Fig. 4, see also Figs. S2 and S3). Some are characterized by a decrease in geopotential height at high latitudes, some others by an increase. Nearly all of them present some anomalous low and high pressure systems over the Southern Ocean but the centres of action are located at different longitudes. The spatial distribution of the trend of the other variables analysed in Fig. 2 also displays a clear contrast between the 11 periods investigated but more common characteristics are present compared to the geopotential height, as indicated by the wide area with significant signals for many of them (Fig. 2). This is illustrated by the trends in ice concentration in Fig. 4: for all the periods, regions with negative trend coexist with ones of positive trends but the latter are much more widespread.

Consequently, the mean of the trend of the geopotential height over the 11 periods is not representative of any of the periods and cannot be dynamically linked with the trend in ice concentration. However, for each of the periods taken individually, many regional changes can be attributed to the atmospheric circulation. We will not go into the details here as the associated processes have already been the subject of many studies. For instance, the 4th selected period is quite similar to the last decades with a decrease of geopotential over Antarctica and in the Pacific sector. This leads to southerly winds in the Ross Sea and higher ice concentration there while the northerly winds in the Bellingshausen Sea cause a decrease of the ice extent in this region (Fig. 4), as discussed in several analyses devoted to the changes observed since 1979 (e.g. Liu et al., 2004; Lefebvre and Goosse, 2008b; Holland and Kwok, 2012; Simpkins et al., 2012; Parkinson and Cavalieri, 2012).

\subsection{Potential influence of the conditions at the beginning of the periods of large increase in ice extent}

In addition to the feedbacks related to ice-ocean interactions and to the influence of the winds discussed above, the initial conditions at the beginning of the periods investigated also play a role in the large positive trends simulated by LOVECLIM: an increase is more likely if ice extent is initially low, the system coming back to its mean state. Indeed, the sea ice extent is on average $0.28 \times 10^{6} \mathrm{~km}^{2}$ lower than the climatological mean of the model at the beginning of the 11 periods and $0.30 \times 10^{6} \mathrm{~km}^{2}$ higher than this mean at the end of the periods. This implies that the large positive trends generally bring the system from an anomalous low extent to an anomalous high extent, the mean over the periods being unsurprisingly close to the long-term average of the model (Fig. 1). Those low sea ice extents are associated with low ice concentrations as expected, particularly in the Southern Pacific and the Weddell Sea (Fig. 5a), and thus with relatively warm conditions at surface (Fig. 5b). This higher heat content of the ocean surface layer is then quickly released to the atmosphere when sea ice extent is increasing and the surface cools down (Fig. 2a, b). Moreover, a lower initial heat content between 100 and $500 \mathrm{~m}$ (Fig. 5c) could contribute to an increase in ice extent as it stabilizes the water column and reduces the amount of heat available to melt sea ice or delay its formation. The signal is, however, not significant at high southern latitudes in our experiments, except in the Pacific sector. The situation for the initial sea surface salinity (Fig. 5d) is even less clear as two processes are in competition. On the one hand, a more stable column due to a lower sea surface salinity would reduce the vertical mixing, the oceanic heat flux towards the surface and thus favour an increase in ice extent. On the other hand, the reduced ice concentrations described in Fig. 5a are often associated with the deep mixed layer and the transfer of warm and salty deep water to the surface, leading to higher surface salinity. This latter effect seems dominant for surface salinity in the Pacific sector while fresher surface layers and more stable columns are generally found in the other sectors at the beginning of a period of large increase in ice extent. 

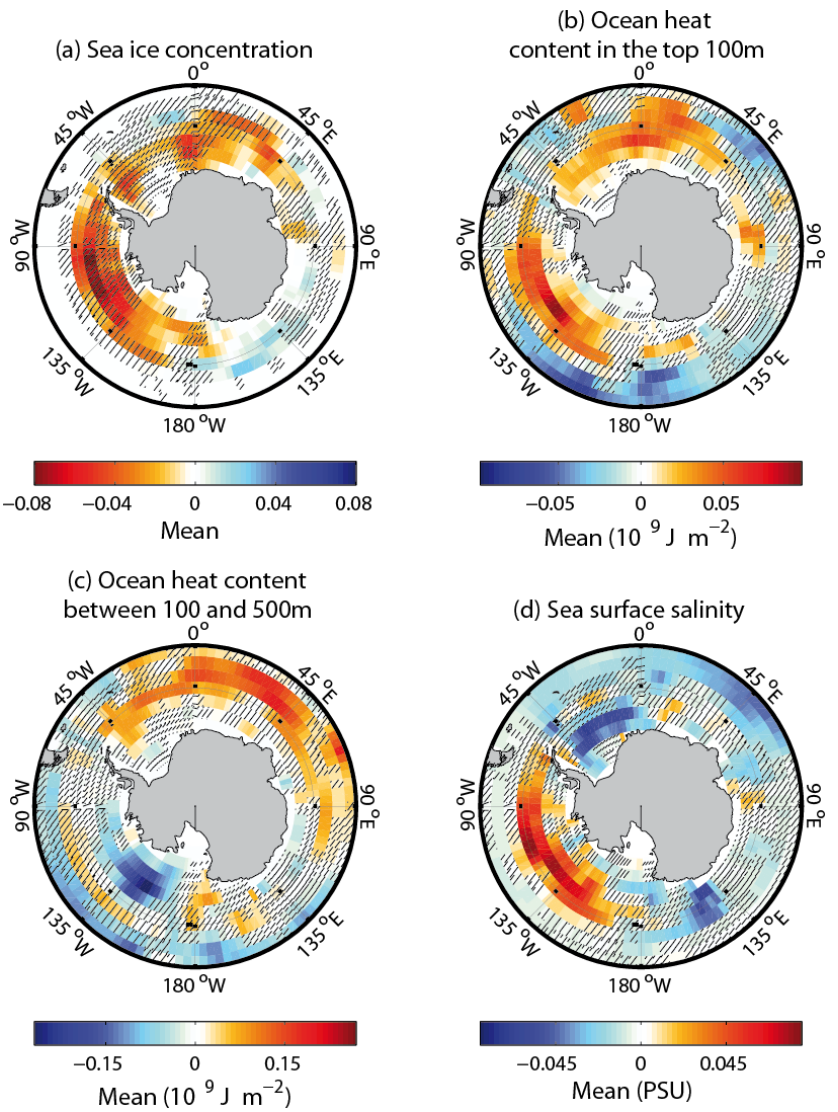

Fig. 5. Anomalies compared to the 1000 year mean averaged over the first year of the 11 periods showing a large increase in Antarctic sea ice extent of (a) ice concentration, (b) ocean heat content in the top $100 \mathrm{~m}\left(\mathrm{~J} \mathrm{~m}^{-2}\right)$, (c) ocean heat content in the layer between 100 and $500 \mathrm{~m}\left(\mathrm{~J} \mathrm{~m}^{-2}\right)$, (d) sea surface salinity. The hatched areas represent the regions for which the mean value over the 11 periods is not significantly different at the $95 \%$ level compared to periods not showing a large increase in ice extent.

\section{A simple model illustrating a possible long-term stabilization of the water column by ice formation}

\subsection{Model description}

Sea ice is formed when the ocean is at its freezing point. This corresponds to the maximum surface density that can be reached for a given salinity in the range that is observed in the Southern Ocean. Any stabilization of the water column at the surface related to the presence of sea ice must therefore be ultimately related to change in salinity. This can be achieved first by a net transport of sea ice to a particular location where it melts, induces a freshwater input at the surface that reduces the salinity, increases the stratification and the stability of the water column. This horizontal transport plays thus a similar role as a positive precipitation minus evaporation $(\mathrm{P}-\mathrm{E})$ budget.

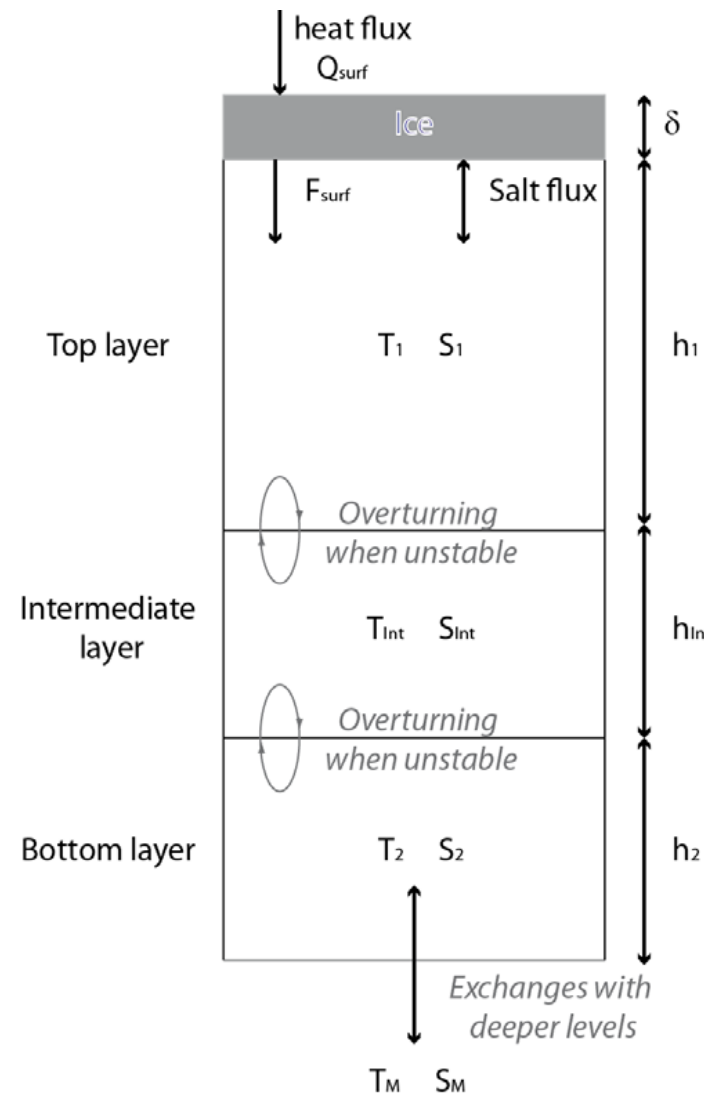

Fig. 6. Schematic representation of the three-level model displaying the dominant processes included and the state variables.

As mentioned in Sect. 3, stabilization can also be obtained because of purely vertical processes. This can be illustrated by means of a very simple model including three levels in the ocean and a potential ice cover (Fig. 6). It is based on the same principles as the one developed by Martinson et al. (1981) in their pioneer work devoted to the big Weddell polynya that occurred in 1974-1976. As in this study we assume that the ice occupies the whole surface with a constant ice thickness (no leads) and we neglect the seasonal variations in mixed layer depth except when it reaches the deeper levels; our first level represents thus the top of the ocean that is mixed every year because of the wind stirring effect or because of a destabilization due to the increase in surface density in winter.

The main difference with Martinson et al. (1981) is that we do not focus on deep convection but rather on modest variations of the mixed layer depth. As a consequence, we have introduced an intermediate level that represents the fraction of the water column that can be incorporated or not in the surface layer in winter depending on the conditions (Fig. 6). The thickness of this level has then been chosen to be of the same order of magnitude as the variations of the mixed layer depth seen in LOVECLIM during the periods of increase in 
ice extent (Fig. 2g). The bottom level may also be entrained in the surface mixed layer but only when the surface forcing is large. This bottom level exchanges heat and salt with the deeper layers (whose temperature and salinity are $T_{M}$ and $S_{M}$, respectively) that are never included in the surface mixed layer in our simple model.

We have also made additional simplifications compared to Martinson et al. (1981), to only include the terms necessary for our purpose. We neglect the freshwater flux at the surface associated with precipitation and evaporation to focus on surface fluxes due to ice formation/melting; the heat flux at the atmosphere interface follows a simple sinusoidal law during the year and is independent of sea ice; there is no exchange between the levels except when one level becomes denser that the one below, leading to an instantaneous mixing of those two levels. Consequently, as the intermediate level is separated from the surface and the deep layers where fluxes are applied, its characteristics do not evolve with time unless mixing with other levels occurs.

The equations for the seven model variables $T_{1}, T_{2}, T_{\mathrm{int}}, S_{1}, S_{2}$, and $S_{\mathrm{Int}}, \delta$ - corresponding to temperature and salinity of the three levels and to ice thickness are

$h_{1} \frac{\mathrm{d} T_{1}}{\mathrm{~d} t}=\frac{F_{\text {surf }}}{\rho_{0} c_{p}}$,

$h_{1} \frac{\mathrm{d} S_{1}}{\mathrm{~d} t}=\sigma \frac{\mathrm{d} \delta}{\mathrm{d} t}$,

$\frac{\mathrm{d} \delta}{\mathrm{d} t}=\frac{1}{\rho_{i} L}\left(-Q_{\text {surf }}-\rho_{0} c_{p} c_{\mathrm{hi}}\left(T_{1}-T_{\mathrm{F}}\right),\right)$

$\frac{\mathrm{d} T_{\text {Int }}}{\mathrm{d} t}=0$,

$\frac{\mathrm{d} S_{\text {Int }}}{\mathrm{d} t}=0$,

$h_{2} \frac{\mathrm{d} T_{2}}{\mathrm{~d} t}=-k_{r}\left(T_{2}-T_{M}\right)$,

$h_{2} \frac{\mathrm{d} S_{2}}{\mathrm{~d} t}=-k_{r}\left(S_{2}-S_{M}\right)$,

using a simple linear equation of state for ocean density $\rho$ :

$\rho^{\prime}=\frac{\rho-\rho_{0}}{\rho_{0}}=-\alpha T+\beta S$.

The surface forcing $Q_{\text {surf }}$ is given by

$Q_{\text {surf }}=A_{\mathrm{F}} \cos (2 \pi t /(365 \cdot 86400))$.

If the ocean is ice free, the flux at the surface of the ocean, $F_{\text {surf }}$ is

$F_{\text {surf }}=Q_{\text {surf }}$,

otherwise it is

$F_{\text {surf }}=-\rho_{0} c_{p} c_{\mathrm{hi}}\left(T_{1}-T_{\mathrm{F}}\right)$.

The meaning of the parameters as well as the values selected in the standard experiment are given in Table 2.

\subsection{Simulations with the three-level model}

When starting from a weakly stratified ocean at $t=0\left(S_{1}=\right.$ $S_{M}-0.2, T_{1}=T_{M}+1.5^{\circ} \mathrm{C}, S_{\text {Int }}=S_{M}-0.1, T_{\text {Int }}=T_{M}+$ $\left.1{ }^{\circ} \mathrm{C}, S_{2}=S_{M}, T_{2}=T_{M}\right)$, the density of the top level becomes higher than the one of the intermediate level the first winter (Fig. 7). This induces mixing and a vertical heat transfer leading to a small warming of the surface. Despite the winter cooling, the water column is always warmer than the freezing point and no sea ice is formed. In summer, the water column is stratified again because of the warming but the salinity remains homogenous in the top and intermediate levels as no mechanism can restore a significant salinity difference between them. Equilibrium is already reached the second year. The intermediate level keeps a cold temperature all year long and mixes with the top level every winter, when the mixed layer corresponds to the top two levels. The bottom level is always separated from the other ones and has constant characteristics during the whole period of integration.

If this equilibrium is perturbed by reducing the heat flux ( $Q_{\text {surf }}$ ) by $20 \mathrm{~W} \mathrm{~m}^{-2}$ during one year only to mimic the impact of a brief cold period on the system, ice is formed in winter (Fig. 8). This leads to an increase in the salinity of the top and intermediate levels because of brine rejection. In the second winter, the surface density is high enough to destabilize and mix the three levels. The exchanges with the bottom level bring salt and heat to the intermediate and top levels, providing a negative feedback as described in detail by Martinson (1990). When sea ice melts in summer, the surface salinity decreases leading to a strong seasonal stratification. In addition to those seasonal effects, the cycle of ice formation and melting has also longer-term effects on the salinity of the three levels. Firstly, the mixing with the upper levels reduces the salinity of the bottom level but this is compensated for by the exchanges with the deeper ocean. Consequently, the temperature and salinity reach equilibrium at $T_{M}$ and $S_{M}$, as expected. Secondly, the salinity of the intermediate level increases during the first two years because of two processes: it interacts with the top level in winter only, when the latter is salty and because of the exchanges with the bottom level. Thirdly, for the top level, two effects of opposite signs are acting. As in the intermediate level, the exchanges with the deep level induce an import of salt. Additionally, salt is exported to the intermediate level in winter while the meltwater is included only in the surface level in summer, resulting in a downward salt flux. In our experiment, the net effect is a slight reduction of the surface salinity in the annual mean. More importantly, this contributes to the strong contrast of salinity between the top and intermediate layers and, after a few years, the water column becomes stable with a top layer decoupled from the other two and thus the winter's mixed layer corresponding to the top layer only. The intermediate layer becomes part of the pycnocline; its temperature and salinity tend to $T_{M}$ and $S_{M}$ as in the bottom 
Table 2. Description of the parameters used in the simple model.

\begin{tabular}{lll}
\hline Symbol & Parameter & Value \\
\hline$\sigma$ & Difference between ocean and sea ice salinity & 30 \\
$\rho_{i}$ & Density of sea ice & $900 \mathrm{~kg} \mathrm{~m}^{-3}$ \\
$L$ & Latent heat of fusion of ice & $3.3 \times 10^{5} \mathrm{~J} \mathrm{~kg}^{-1}$ \\
$\rho_{0}$ & Standard density of the ocean & $10^{3} \mathrm{~kg} \mathrm{~m}^{-3}$ \\
$c_{p}$ & Heat capacity of sea water & $4 \times 10^{3} \mathrm{~J} \mathrm{~K}^{-1} \mathrm{~kg}^{-1}$ \\
$c_{\mathrm{hi}}$ & Heat exchange coefficient between ocean and sea ice & $3 \times 10^{-4} \mathrm{~m} \mathrm{~s}^{-1}$ \\
$k_{r}$ & Strength of the nudging & $h_{2} /\left(12 \mathrm{months}^{-1}\right.$ \\
$\alpha$ & Thermal expansion coefficient & $5.8 \times 10^{-5} \mathrm{~K}^{-1}$ \\
$\beta$ & Haline contraction coefficient & $8 \times 10^{-4}$ \\
$T_{\mathrm{F}}$ & Freezing point temperature & $-1.8^{\circ} \mathrm{C}$ \\
$h_{1}$ & Thickness of the top model level & $100 \mathrm{~m}$ \\
$h_{\text {Int }}$ & Thickness of the intermediate model level & $25 \mathrm{~m}$ \\
$h_{2}$ & Thickness of the bottom model level & $25 \mathrm{~m}$ \\
$T_{M}$ & Deep ocean temperature & $-1.0^{\circ} \mathrm{C}$ \\
$S_{M}$ & Deep ocean salinity & 35 \\
$A_{\mathrm{F}}$ & Amplitude of the seasonal cycle of the surface heat flux & $150 \mathrm{~W} \mathrm{~m}{ }^{-2}$ \\
\hline
\end{tabular}

layer. As a consequence, the temperature and salinity of the intermediate layer are higher at equilibrium than in the initial condition, ice is formed every winter despite the fact that the surface heat fluxes are identical as in the control case after the first year, and the system never reaches the state observed before the perturbation.

\subsection{Discussion and limitations of the approach}

For the same surface fluxes and deep ocean characteristics, this simple model has thus two types of equilibrium states: one without sea ice and one with a seasonal ice cover, and the system can shift from one to another as a result of a perturbation. When comparing those two states, we note that the presence of sea ice is associated with lower surface salinity, shallower mixed layer depth and warming at intermediate depth without any change in annual mean surface freshwater fluxes. This has clear similarities with the changes obtained in LOVECLIM during the periods of large sea ice extent increase. We should, however, stress again at this stage that the mechanisms described here are only feedbacks in reaction to an initial change. They could not alone explain any long-term trend but could potentially amplify a perturbation, coming for instance from a modification of the winds, in order to sustain large variations of the ice extent as the ones simulated in the control experiment of LOVECLIM.

We must also be very careful with such simple systems that can display multiple equilibriums or not, for instance in function of the type of boundary conditions that are imposed (e.g. Mikolajewicz and Maier-Reimer, 1994; Lenderink and Haarsma, 1994, 1996), or that can be strongly dependant on the parameters and initial conditions used. Furthermore, only one process is included here while additional feedbacks (such as the ones related to the changes in surface fluxes induced by the presence of ice) or the addition of a net surface freshwater flux can modify the existence or the stability properties of the two equilibriums. We do not want, however, to make our model more complex to be more realistic. Thanks to its simplicity, it has allowed us to present an example underlining in a straightforward way the stabilization effect of the downward transport of salt associated with brine release in winter, when the mixed layer is deep, and ice melting in summer, when mixed layer is shallow. This does not mean that we claim that some regions of the real Southern Ocean could have two (or more) equilibriums for present-day conditions, one with a seasonal ice cover or one without ice, or that the sequence of processes illustrated in this very simple model could be observed directly. Nevertheless, it clearly shows the potential relevance of the proposed mechanism to explain some of the characteristics of the variability of the ice extent simulated by LOVECLIM.

\section{Trend over the last decades}

On average, the historical simulations performed in the framework of CMIP5 display a decrease of the ice extent over the period 1979-2005 in response to anthropogenic forcing (Turner et al., 2013; Zunz et al., 2013; Mahlstein et al., 2013). Nevertheless, a few of the individual members show a weak increase (see for instance Fig. 3 of Zunz et al., 2013). Although the respective role of the forcing and internal variability has not been assessed for the majority of models, this likely corresponds to cases where the latter is able to overwhelm the forced model response (Zunz et al., 2013; Mahlstein et al., 2013; Polvani and Smith, 2013). This is consistent with the fact that, for the models providing several members, such an increase is observed in some of the members but not in all of them. 
a) Temperature
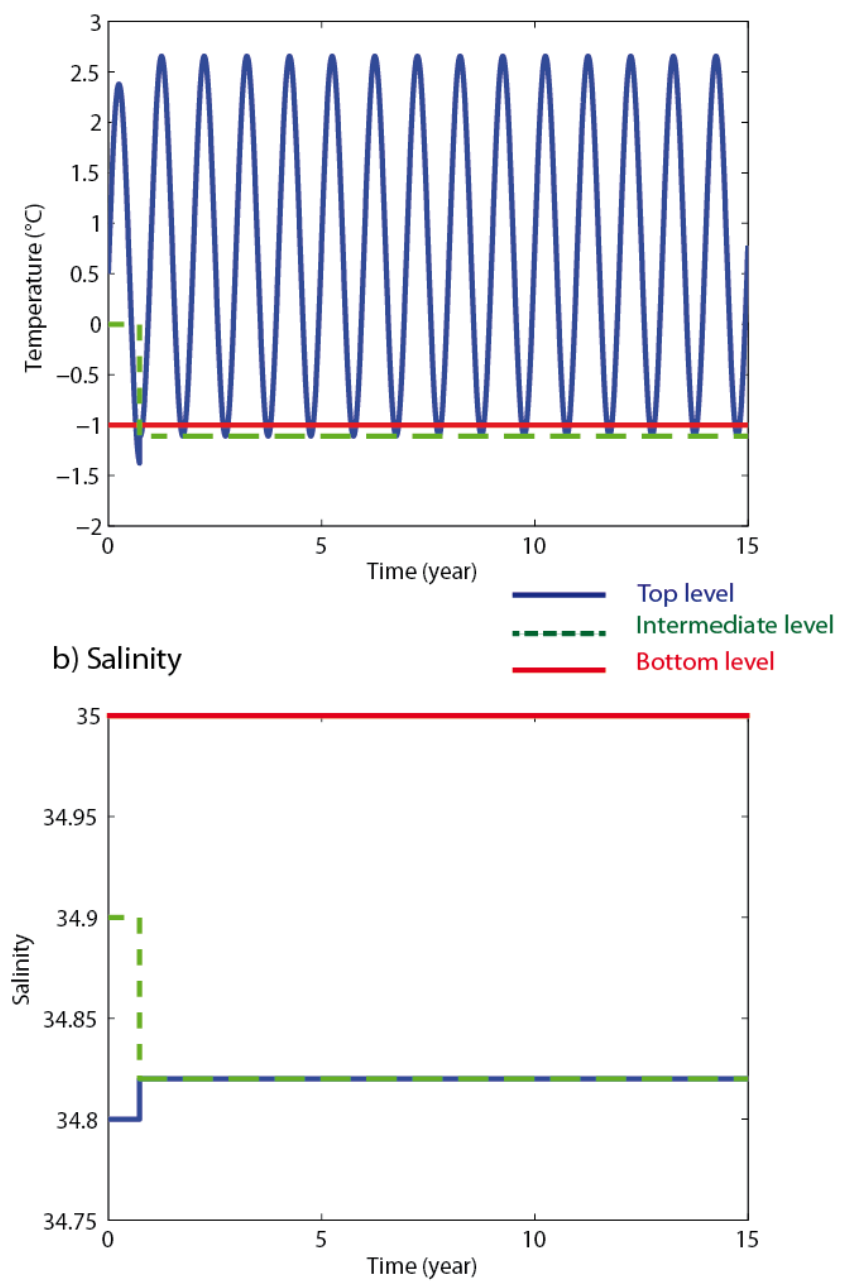

Fig. 7. (a) Temperature $\left({ }^{\circ} \mathrm{C}\right)$ and (b) salinity in an experiment performed with the three-level model initialized from a weakly stratified state. The value of the top level is in blue, the intermediate level in green and the bottom one is in red. In this configuration, the top two levels interact every winter and no ice is formed.

In all those simulations, the increase in total ice extent is associated with an increase in ice concentration in some sectors of the Southern Ocean and a decrease in other regions (Fig. 9). Furthermore, the spatial distribution of the sea ice concentration trends strongly varies from one model to another and even between different simulations performed with the same model. This is in agreement with the hypothesis deduced from LOVECLIM results (see Fig. 4) that a positive trend in ice extent could be obtained from very different spatial patterns.

Thanks to data assimilation, LOVECLIM can be constrained to follow the observed changes over the last decades, but the constraint is relatively weak using the technique applied here as it comes only from surface temperature data which are very sparse at high latitudes (HadCRUT3 data set, a) Temperature
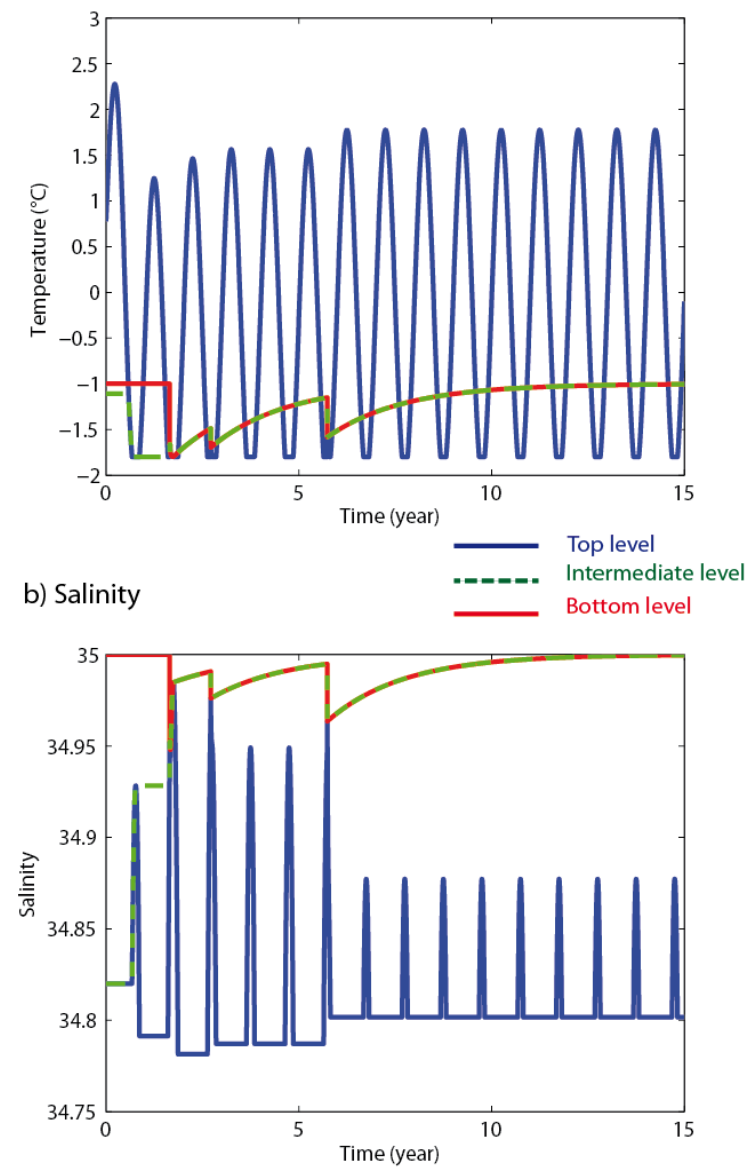

c) Ice thickness

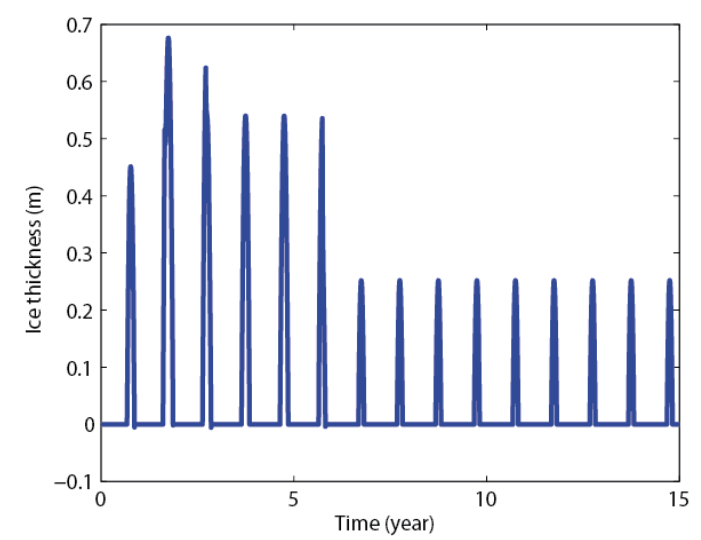

Fig. 8. (a) Temperature $\left({ }^{\circ} \mathrm{C}\right)$, (b) salinity, and (c) sea ice thickness (m) in the three-level model in response to a reduction of the surface heat flux during the first year. The value of the top level is in blue, the intermediate level is in green, and the bottom one is in red. Because of the perturbation, strong sea ice formation initially destabilizes the water column but the downward transport of salt out of the top level finally leads to a stable water column during all the seasons after seven years. 

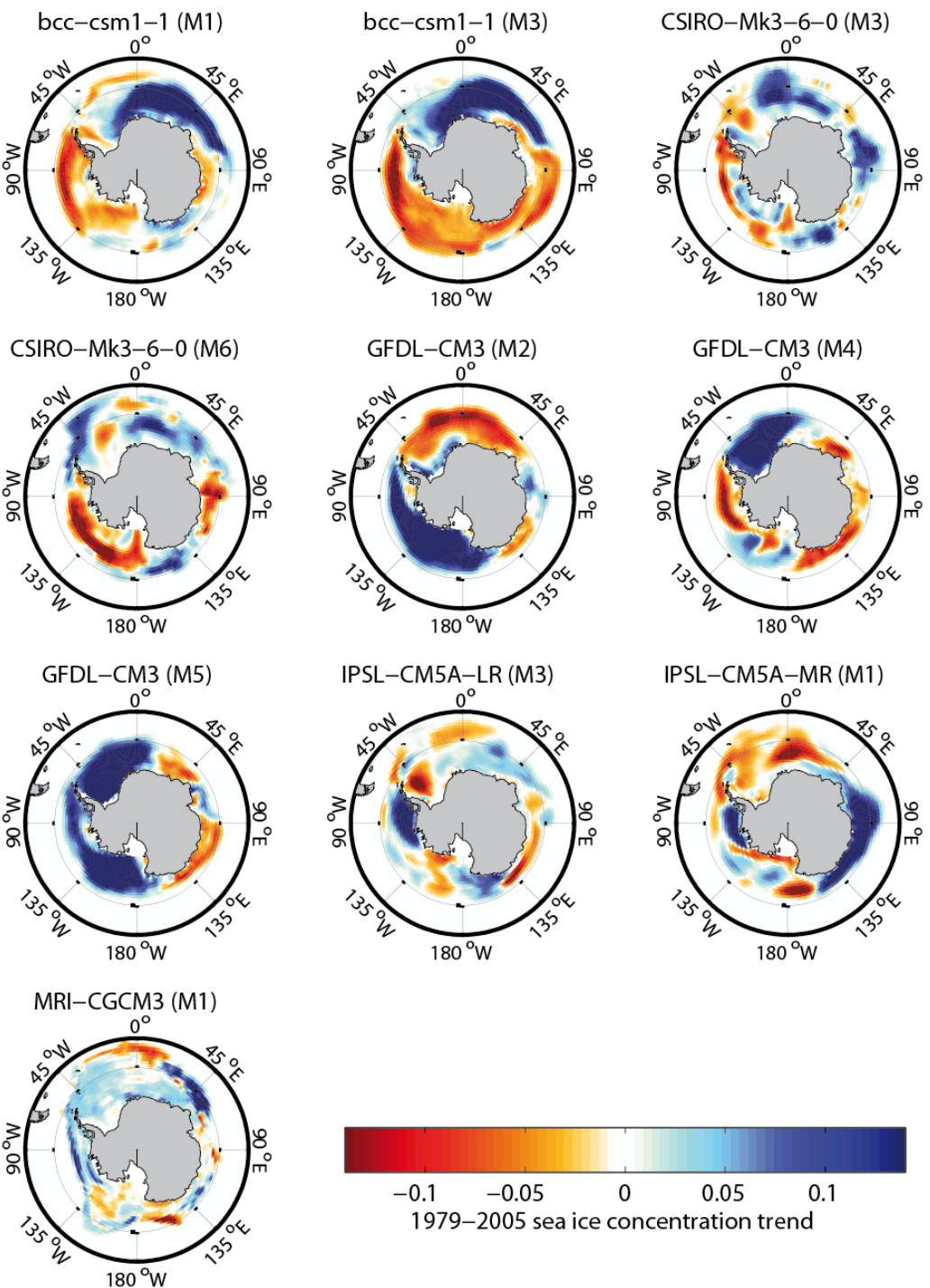

Fig. 9. Ice concentration trends over the period 1979-2005 in historical simulations performed with CGCMs in the framework of CMIP5. Only the simulations characterized by an increase in sea ice extent over this period are represented here. The trends are scaled to represent 27 year changes. The name of the model (Table 3) and the corresponding member of the ensemble (if several members are available in CMIP5 archive) are mentioned on the top of each panel.

Table 3. Model name and modelling centre corresponding to the CGCMs used to study the trend in sea ice extent over the period 1979-2005.

\begin{tabular}{|c|c|c|}
\hline Model name & Institute ID & Modelling center \\
\hline BCC-CSM1.1 & $\mathrm{BCC}$ & $\begin{array}{l}\text { Beijing Climate Center, China Meteorological Admin- } \\
\text { istration }\end{array}$ \\
\hline CSIRO-Mk3.6.0 & CSIRO-QCCCE & $\begin{array}{l}\text { Commonwealth Scientific and Industrial Research Or- } \\
\text { ganisation in collaboration with Queensland Climate } \\
\text { Change Centre of Excellence }\end{array}$ \\
\hline GFDL-CM3 & NOAA GFDL & NOAA Geophysical Fluid Dynamics Laboratory \\
\hline IPSL-CM5A-LR & IPSL & Institut Pierre-Simon Laplace \\
\hline IPSL-CM5A-MR & IPSL & Institut Pierre-Simon Laplace \\
\hline MRI-CGCM3 & MRI & Meteorological Research Institute \\
\hline
\end{tabular}



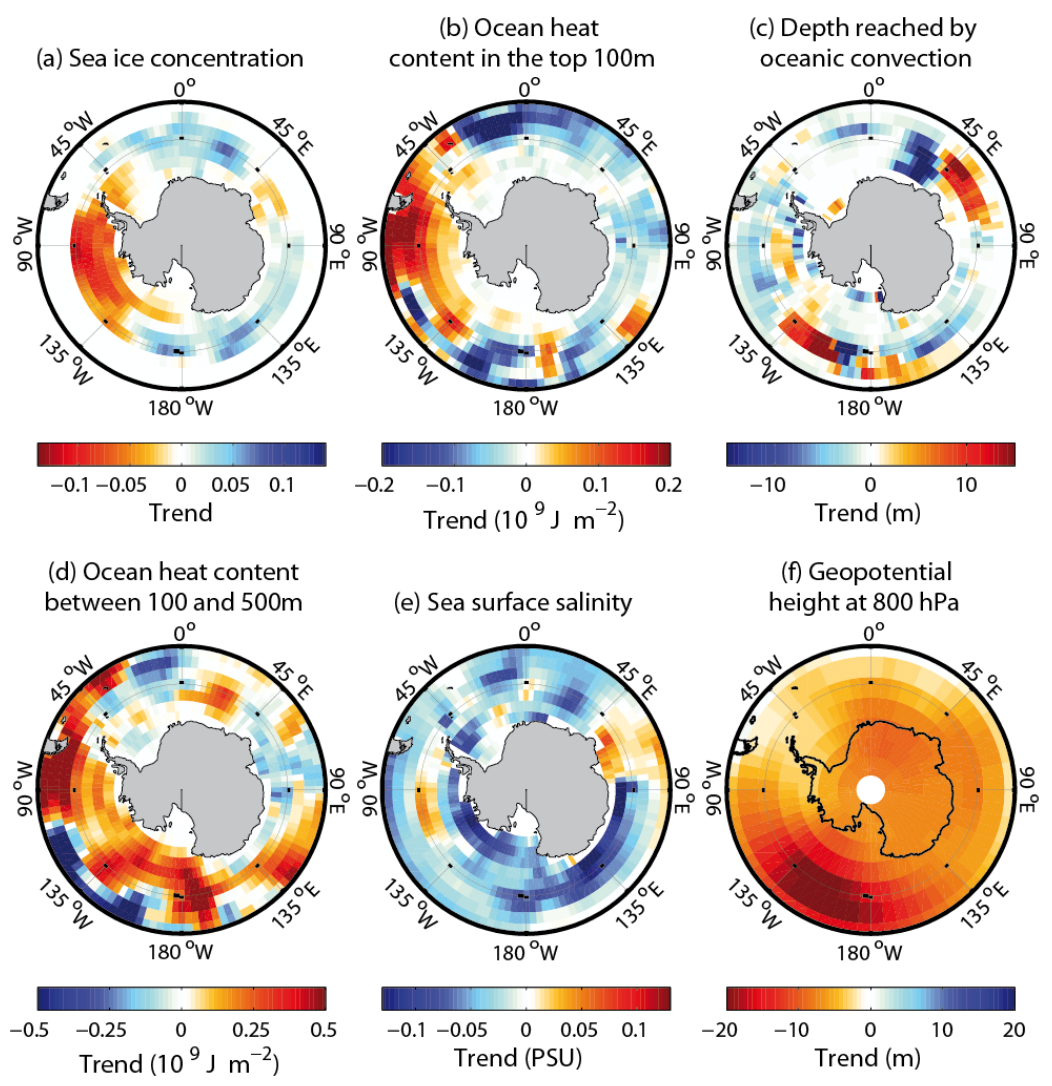

Fig. 10. Trends over the period 1979-2009 in a simulation with LOVECLIM using data assimilation scaled to represent the 31 year changes of (a) ice concentration, (b) ocean heat content in the top $100 \mathrm{~m}\left(\mathrm{~J} \mathrm{~m}^{-2}\right)$, (c) depth reached by oceanic convection (m), (d) ocean heat content in the layer between 100 and $500 \mathrm{~m}\left(\mathrm{~J} \mathrm{~m}^{-2}\right)$, (e) sea surface salinity, and (f) geopotential height at $800 \mathrm{hpa}(\mathrm{m})$.

Brohan et al., 2006). This has the advantage to introduce limited perturbations in the model dynamics (e.g. Dubinkina et al., 2011; Dubinkina and Goosse, 2013) and to provide estimates over the 20th century that are as homogenous as possible (Goosse et al., 2009). In comparison, the atmospheric reanalyses often have shifts in the late 1970s associated with the introduction of satellite measurements in the set of assimilated data, which leads to spurious long-term trends (Kistler et al., 2001; Fichefet et al., 2003; Marshall, 2003). Nevertheless, because of this weak constraint and because of the low resolution of LOVECLIM, we do not expect to simulate the details of the observed trends. Even sea ice-ocean models driven by the best estimates of atmospheric forcing have trouble in reproducing the sea ice variability in the Southern Ocean over the last decades (Fichefet et al., 2003; Zhang, 2007; Massonnet et al., 2011). We are, however, able to simulate a large decrease of the ice concentration in the Bellingshausen Sea and in the western Weddell Sea and an increase in the majority of the other sectors in good agreement with observations (Fig. 10a). The overall trend in ice extent is of $-38 \pm 93 \times 10^{3} \mathrm{~km}^{2}$ per decade over the period 1979-2009. This implies that the ensemble mean of the simulation with data assimilation underestimates the observed increase. The simulated trend in this experiment is still much closer to the observed one than the mean of an ensemble of simulations performed with LOVECLIM without data assimilation $\left(-152 \pm 49 \times 10^{3} \mathrm{~km}^{2}\right.$ per decade). The disagreement with observations is mainly due to a too widespread decrease of the sea ice concentration in the Pacific sector of the Southern Ocean that expands in parts of the Ross Sea. This is not critical as our main objective is not to examine the details of the spatial distribution of the changes but to focus on the processes studied in Sects. 3 and 4 in order to estimate if they have likely played a role in the recent large-scale changes of the sea ice cover. Nevertheless, those biases will have some implications for our analyses as mentioned below.

As discussed for the periods of large increase in sea ice extent in the control experiment, a decrease in the surface air temperature and in the heat content of the surface layer is noticed in regions where ice concentration is increasing (Fig. 10b). By contrast, the simulated heat content of the surface layer increases in the eastern Pacific sector and is likely overestimated because of the biases in the simulation in this region. The depth of the mixed layer is generally decreasing where sea ice concentration is increasing such as in the Weddell Sea and between $90^{\circ}$ and $180^{\circ} \mathrm{E}$ (Fig. 10c). It becomes 
deeper close to $50^{\circ} \mathrm{E}$ where sea ice concentration is decreasing while the link between sea ice and mixed layer depth is less clear in the Pacific sector. As in the control experiment, the oceanic heat content between 100 and $500 \mathrm{~m}$ is increasing in the majority of the regions during the period 19792009 (Fig. 10d) but the magnitude is stronger than in the control experiment (Fig. 2g). The changes in salinity are also stronger, with a freshening nearly everywhere in the Southern Ocean (Fig. 10e). As the warming at depth and the surface freshening are also found in the simulations without data assimilation, the forcing contributes partly to those trends in the simulation with data assimilation.

The spatial pattern of the changes in sea ice concentration is driven by a general decrease of the geopotential height at high latitudes with maximum changes around $150^{\circ} \mathrm{W}$ (Fig. 10f). This induces an increase in the northward winds in the western part of the Ross Sea and of southward wind anomalies in the Bellingshausen Sea, which causes the decrease in sea ice concentration there. Compared to observations that show maximum trends in geopotential height and surface pressure over the Bellingshausen Sea, the changes obtained in LOVECLIM with data assimilation are thus shifted westward. This explains why the trend in sea ice concentration is negative in parts of the Ross Sea in contrast to observations.

The simulated results over the last 30 years appear thus compatible, at least in some sectors of the Southern Ocean, with a shallower mixed layer and heat storage below the mixed layer which are characteristic of our control experiment during the period of large increase in the ice extent. The last decades also display a clear freshening in our experiments. Long observed time series to test those model results are rare at the high latitudes of the Southern Ocean but, in the Ross Sea, a freshening at all depths over the continental shelf and a warming at intermediate depths (around $300 \mathrm{~m}$ ) north of it have been observed since the 1970s (Jacobs et al., 2002; Orsi and Wiederwohl, 2009). At a larger scale, Durack and Wijffels (2010) suggest a freshening at high latitudes in the Ross Sea sector and a salinity increase in the Bellingshausen Sea over the last 50 years. In the Weddell Sea, the temperature of Warm Deep Water (WDW) is characterized by strong decadal fluctuations, probably linked to the variability of the oceanic circulation, but also by a small warming trend (Fahrbach et al., 2011). Although very fragmentary, those observations are generally consistent with our simulation with data assimilation (except for the simulated salinity decrease in the Bellingshausen Sea) and with the mechanism proposed to explain the natural variability in LOVECLIM. This is encouraging but could not be considered as a definitive proof that the stabilization of the water column associated with the presence of ice is playing a dominant role in the recent changes as many causes may trigger a positive ice-ocean feedback leading to a stronger stratification, larger heat storage at depth and lower vertical heat transfer (Fig. 3).
The simulation with data assimilation displays a decrease in ice extent between the 1960s and the late 1970s. This is consistent with earlier simulations performed with data assimilation using a simpler technique (Goosse et al., 2009), showing that this result is robust to modifications of our experimental design. The reconstructions are relatively uncertain over this period. Nevertheless, early satellite data suggest that the sea ice extent was larger in 1964 as well as in the early 1970s than after 1979 (Cavalieri et al., 2003; Meier et al., 2013). Indirect estimates based on whaling records or derived from ice core measurements are subject to larger uncertainties but they also independently suggest a larger ice extent before 1979 (de la Mare, 1977; Curran et al., 2003; Cotté and Guinet, 2007; Abram et al., 2010). Nevertheless, the sea ice extent in 1979 in the simulation with data assimilation is very close to the mean of the ensemble of simulations without data assimilation. This suggests that the simulated changes after 1979 in the simulation with data assimilation are not associated with the recovery from a low value, a factor that contributes to the ice extent increase in some of the periods studied in the control experiment.

\section{Conclusions}

In the simulations we have analysed, the multidecadal variability of the Antarctic sea ice is not associated with a dominant spatial pattern. Each 30 year period characterized by a large increase in sea ice extent in a control simulation performed with LOVECLIM displays positive trend in ice concentration in the majority of the sectors of the Southern Ocean but also negative ones in regions that differ among those periods. This conclusion is also valid for the CGCMs that show a positive trend over the last decades.

Nevertheless, two main conclusions have been derived from our experiments. First, a low initial sea ice extent favours a subsequent large increase since a return to mean conditions would already contribute to this increase. This condition is, however, not required in all the cases analysed. Secondly, a larger mean ice concentration is generally associated with a stabilization of the water column, storage of heat at depth, and a reduction of the vertical oceanic heat flux that tends to further cool the ocean surface. This feedback amplifies the variability of the system and provides the memory required to sustain large multidecadal variations. The stabilization of the water column can be due to a net inflow of sea ice (and thus of freshwater) to a region where it melts in summer, favouring ice formation the following year at the same location. It can also be caused by the downward transport of salt associated with the incorporation of the brine released in winter in a deeper oceanic mixed layer than the meltwater in summer, which potentially modifies the vertical structure of the water column for several years. Compared to an ice free situation, ice formation during a particular year (for instance, because of a large cooling) implies a decrease of the surface 
salinity and a salinity increase below the mixed layer in summer, but also on the longer term as illustrated here using a simple model. Parameterizations have been suggested to distribute the salt released during ice formation over a depth range function of the stratification of the water column, a part of the flux being directly included in the whole mixed layer or below it (e.g. Duffy and Caldeira, 1999; Nguyen et al., 2009). Such a parameterization is not included in LOVECLIM but could amplify the influence of the downward transport of salt on the ocean stratification.

The important oceanic feedback has its origin in the low stratification of the Southern Ocean and in the presence of relatively warm water at depth. It has thus different magnitudes in different regions as a function of the vertical structure of the water column. However, it can be active in nearly all the areas at high southern latitudes, explaining why a large variability of the ice concentration can be found nearly everywhere in our experiments. Furthermore, it provides only an amplification mechanism, which must be triggered, meaning that the spatial structure and the ultimate origin of the trend of sea ice extent during a particular period have to be found in other processes. In our experiments, it is mainly governed by the winds (in agreement with what has been observed over the last decades) that bring cold air and transports sea ice, inducing the initial anomaly in sea ice concentration. Additional freshwater fluxes due to higher precipitation rates or the meltwater inflow from ice shelves are not required but they can also be the origin of additional ice formation.

Nevertheless, whatever the original trigger, the amplification of the initial perturbation crucially depends on the modification in the vertical stratification caused by the presence of sea ice. This feedback combines then its effect with others such as the classical temperature-albedo feedback (e.g. Ebert and Curry, 1993; Qu and Hall, 2006; Flanner et al., 2011; Kay et al., 2011) to determine the magnitude of the changes. This dominant role of feedbacks compared to the initial cause of the event may also explain why it appears difficult to attribute the sea ice development observed during a particular period, as for instance the last 30 years, to a specific origin.

It has been demonstrated that ice-ocean interactions can lead to negative feedbacks playing an essential role in the Southern Ocean. At the seasonal timescale, the upward vertical heat transport associated with the mixed layer deepening due to brine rejection in winter strongly limits ice formation and a further mixed layer deepening, stabilizing the system (Martinson, 1990). In response to a warming, in particular due to anthropogenic forcing, the modification of sea ice freshwater and salt fluxes contributes to heat storage at depth and to a reduction of the upward heat fluxes that moderate the surface changes leading also to a negative feedback (Bitz et al., 2006; Zhang 2007; Kirkman and Bitz, 2010).

By contrast, on interannual timescales, ice-ocean interactions can lead to positive feedbacks. To illustrate this, we have performed a sensitivity experiment with LOVECLIM in which the ice-ocean salt and freshwater fluxes are following a prescribed seasonal cycle, which is repeated every year, derived from the mean cycle of the control experiment. This implies that all the positive and negative feedbacks related to the interannual variations of the brine release during ice formation and the freshwater input to the ocean surface when ice melts are not operating anymore. As a result, the interannual variability of the sea ice extent is decreasing by nearly $25 \%$, demonstrating the importance of the positive feedbacks due to those fluxes in the model.

The positive feedback associated with ice formation mentioned here is clearly different from the one implied in deep convection events that may lead to polynya formation or strongly reduced ice concentration (e.g. Martinson et al., 1981; Mikolajewicz and Maier-Reimer, 1990; Stöessel and Kim, 2001; Martin et al., 2013). During the years following such an event, the vertical stratification remains low and could easily be destroyed in winter, maintaining deep mixing during several years and potentially leading to multidecadal variations of the sea ice extent. In the mechanism illustrated here, the modifications of the mixed layer are much weaker. No major change in the vertical structure is required, only the shape of the pycnocline and the position of its top are modified. Another important difference is that such a deep convection event is possible only in some restricted regions of the Southern Ocean while the downward transport of salt associated with ice formation can occur over a wide domain. Finally, the stabilization of the water column associated with the presence of sea ice is a feedback, it is not the original cause of the variability. By contrast, it has been suggested that the ice-ocean interactions may induce a slow drift of the properties of the water column driving, in combination with other atmospheric and oceanic processes, the shift from a situation without polynya to a polynya mode (e.g. Martin et al., 2013).

The feedback we have discussed appears robust and provides a reasonable explanation for some important characteristics of the simulations performed with LOVECLIM and CGCMs as well as for the recent changes (although the available observations are not sufficient to demonstrate clearly its importance or to discard it). It is based on sound physical principles and can be described in a simple model. Its exact magnitude is, however, relatively uncertain: it strongly depends on the mean state of the system (in particular the mean seasonal cycle of the mixed layer depth) and on the impact of surface fluxes associated with melting and freezing on vertical mixing. Current models have biases in their representation of those processes. Because of their importance, it is crucial to improve them in order to have a better understanding of the relative contribution of internal variability and of the forced response in the recent changes and thus a higher confidence in the projections for the 21 st century. 
Supplementary material related to this article is available online at http://www.the-cryosphere.net/8/453/ 2014/tc-8-453-2014-supplement.pdf.

Acknowledgements. We would like to thank Antoine Barthélemy, Sally Close and Svetlana Dubinkina for their helpful comments on the manuscript. We acknowledge the World Climate Research Programme's Working Group on Coupled Modelling, which is responsible for CMIP. For CMIP the US Department of Energy's Program for Climate Model Diagnosis and Intercomparison provides coordinating support and led development of software infrastructure in partnership with the Global Organization for Earth System Science Portals. H. Goosse is a senior research associate with the Fonds National de la Recherche Scientifique (F.R.S.FNRS-Belgium). V. Zunz is a research fellow with the Fonds pour la formation à la Recherche dans l'Industrie et dans l'Agronomie (FRIA-Belgium). This work has been performed in the framework of the ESF HOLOCLIP project (a joint research project of the European Science Foundation PolarCLIMATE program, which is funded by national contributions from Italy, France, Germany, Spain, Netherlands, Belgium and the United Kingdom) and is supported by the F.R.S.-FNRS and by the Belgian Federal Science Policy Office (Research Program on Science for a Sustainable Development). Computational resources have been provided by the supercomputing facilities of the Université catholique de Louvain (CISM/UCL) and the Consortium des Equipements de Calcul Intensif en Fédération Wallonie Bruxelles (CECI) funded by the Fond de la Recherche Scientifique de Belgique (FRS-FNRS). This is HOLOCLIP contribution 21.

Edited by: R. Lindsay

\section{References}

Abram, N. J., Thomas, E. R., McConnell, J. R., Mulvaney, R., Bracegirdle, T. J., Sime, L. C., and Aristarain, A. J.: Ice core evidence for a 20th century decline of sea ice in the Bellingshausen Sea, Antarctica, J. Geophys. Res., 115, D23101, doi:10.1029/2010JD014644, 2010.

Beckmann, A. and Timmermann, R.: Circumpolar influences on the Weddell Sea: Indication of an Antarctic Circumpolar Coastal Wave, J. Climate, 14, 3785-3792, doi:10.1175/15200442(2001)014<3785:CIOTWS>2.0.CO;2, 2001.

Bintanja, R., van Oldenborgh, G. J., Drijfhout, S. S., Wouters, B., and Katsman, C. A.: Important role for ocean warming and increased ice-shelf melt in Antarctic sea-ice expansion, Nat. Geosci., 6, 376-379, doi:10.1038/ngeo1767, 2013.

Bitz, C. M., Gent, P. R., Woodgate, R. A., Holland, M. M., and Lindsay, R.: The influence of sea ice on ocean heat uptake in response to increasing $\mathrm{CO}_{2}$, J. Climate, 19, 2437-2450, doi:10.1175/JCLI3756.1, 2006.

Brohan P., Kennedy, J. J., Harris, I., Tett, S. F. B., and Jones, P. D.: Uncertainty estimates in regional and global observed temperature changes: A new data set from 1850, J. Geophys. Res., 111, D12106, doi:10.1029/2005JD006548, 2006.

Brovkin, V., Bendtsen, J., Claussen, M., Ganopolski, A., Kubatzki, C., Petoukhov, V., and Andreev, A.: Carbon cycle, vegetation and climate dynamics in the Holocene: experiments with the CLIMBER-2 model, Global Biogeochem. Cy., 16, 86-1-86-20, doi:10.1029/2001GB001662, 2002.

Cavalieri, D. J. and Parkinson, C. L.: Antarctic sea ice variability and trends, 1979-2006, J. Geophys. Res., 113, C07004, doi:10.1029/2007JC004564, 2008.

Cavalieri, D. J. and Parkinson, C. L.: Arctic sea ice variability and trends, 1979-2010, The Cryosphere, 6, 881-889, doi:10.5194/tc6-881-2012, 2012.

Cavalieri, D. J., Parkinson, C. L., and Vinnikov, K. Y.: 30year satellite record reveals contrasting Arctic and Antarctic decadal sea ice variability, Geophys. Res. Lett., 30, 1970, doi:10.1029/2003GL018931, 2003.

Close, S. and Goosse, H.: Entrainment-driven modulation of Southern Ocean mixed layer and sea ice variability in CMIP5 models, J. Geophys. Res., 118, 2811-2827, doi:10.1002/jgrc.20226, 2013.

Comiso, J. C. and Nishio, F.: Trends in the sea ice cover using enhanced and compatible AMSR-E, SSM/I, and SMMR data, J Geophys. Res., 113, C02S07, doi:10.1029/2007JC004257, 2008.

Cotté, C. and Guinet C.: Historical whaling records reveal major regional retreat of Antarctic sea ice, Deep Sea Res. Part I Oceanogr. Res. Pap., 54, 243-252, doi:10.1016/j.dsr.2006.11.001, 2007.

Curran, M. A., van Ommen, T. D., Morgan, V. I., Phillips, K. L., and Palmer, A. S.: Ice core evidence for Antarctic sea ice decline since the 1950s, Science, 232, 1203-1206, doi:10.1126/science.1087888, 2003.

de la Mare, W. K.: Abrupt mid-twentieth-century decline in Antarctic sea-ice extent from whaling records, Nature, 389, 57-60, doi:10.1038/37956, 1997.

Dubinkina, S. and Goosse, H.: An assessment of particle filtering methods and nudging for climate state reconstructions, Clim. Past, 9, 1141-1152, doi:10.5194/cp-9-1141-2013, 2013.

Dubinkina, S., Goosse, H., Sallaz-Damaz, Y., Crespin, E., and Crucifix, M.: Testing a particle filter to reconstruct climate changes over the past centuries, Int. J. Bifurcat. Chaos, 21, 3611-3618, doi:10.1142/S0218127411030763, 2011.

Duffy, P. B. and Caldeira, K. G.: Sensitivity of simulated salinities in a three-dimensional ocean general circulation model to vertical mixing of destabilizing surface fluxes, Clim. Dynam., 15, 81-88, 1999.

Dufresne, J. L., Foujols, M.-A., Denvil, S., Caubel, A., Marti, O., Aumont, O., Balkanski, Y., Bekki, S., Bellenger, H., Benshila, R., Bony, S., Bopp, L., Braconnot, P., Brockmann, P., Cadule, P., Cheruy, F., Codron, F., Cozic, A., Cugnet, D., de Noblet, N., Duvel, J.-P., Ethé, C., Fairhead, L., Fichefet, T., Flavoni, S., Friedlingstein, P., Grandpeix, J.-Y., Guez, L., Guilyardi, E., Hauglustaine, D., Hourdin, F., Idelkadi, A., Ghattas, J., Joussaume, S., Kageyama, M., Krinner, G., Labetoulle, S., Lahellec, A., Lefebvre, M.-P., Lefevre, F., Levy, C., Li, Z. X., Lloyd, J., Lott, F., Madec, G., Mancip, M., Marchand, M., Masson, S., Meurdesoif, Y., Mignot, J., Musat, I., Parouty, S., Polcher, J., Rio, C., Schulz, M., Swingedouw, D., Szopa, S., Talandier, C., Terray, P., Viovy, N., and Vuichard, N.: Climate change projections using the IPSL-CM5 Earth System Model: from CMIP3 to CMIP5, Clim. Dynam., 40, 2123-2165, doi:10.1007/s00382-012-1636-1, 2013. 
Durack, P. and Wijffels, S. E.: Fifty-year trends in global ocean salinities and their relationship to broad-scale warming, J. Climate, 23, 4342-4362, doi:10.1175/2010JCLI3377.1, 2010.

Ebert, E. E. and Curry, J. A.: An intermediate one-dimensional thermodynamic sea ice model for investigating iceatmosphere interactions, J. Geophys. Res., 98, 10085-10109, doi:10.1029/93JC00656, 1993.

Fahrbach, E., Hoppema, M., Rohardt, G., Boebel, O., Klatt, O., and Wisotzki, A.: Warming of deep and abyssal water masses along the Greenwich meridian on decadal timescales: The Weddell gyre as a heat buffer, Deep-Sea Res. Pt. II, 58, 2509-2523, doi:10.1016/j.dsr2.2011.06.007, 2011.

Fichefet, T. and Morales Maqueda, M. A.: Sensitivity of a global sea ice model to the treatment of ice thermodynamics and dynamics, J. Geophys. Res., 102, 12609-12646, doi:10.1029/97JC00480, 1997.

Fichefet, T. and Morales Maqueda, M. A.: Modelling the influence of snow accumulation and snow-ice formation on the seasonal cycle of the Antarctic sea-ice cover, Clim. Dynam., 15, 251-268, doi:10.1029/1999GL002397, 1999.

Fichefet, T., Tartinville, B., and Goosse, H.: Antarctic sea ice variability during 1958-1999: A simulation with a global ice-ocean model, J. Geophys. Res., 108, 3102, doi:10.1029/2001JC001148, 2003.

Flanner, M. G., Shell, K. M., Barlage, M., Perovich, D. K., and Tschudi, M. A.: Radiative forcing and albedo feedback from the Northern Hemisphere cryosphere between 1979 and 2008, Nat. Geosci., 4, 151-155, doi:10.1038/ngeo1062, 2011.

Goosse, H. and Fichefet T.: Importance of ice-ocean interactions for the global ocean circulation: a model study, J. Geophys. Res., 104, 23337-23355, doi:10.1029/1999JC900215, 1999.

Goosse, H., Lefebvre, W., de Montety, A., Crespin, E., and Orsi, A.: Consistent past half-century trends in the atmosphere, the sea ice and the ocean at high southern latitudes, Clim. Dynam., 33, 999-1016, doi:10.1007/s00382-008-0500-9, 2009.

Goosse, H., Brovkin, V., Fichefet, T., Haarsma, R., Huybrechts, P., Jongma, J., Mouchet, A., Selten, F., Barriat, P.-Y., Campin, J.M., Deleersnijder, E., Driesschaert, E., Goelzer, H., Janssens, I., Loutre, M.-F., Morales Maqueda, M. A., Opsteegh, T., Mathieu, P.-P., Munhoven, G., Pettersson, E. J., Renssen, H., Roche, D. M., Schaeffer, M., Tartinville, B., Timmermann, A., and Weber, S. L.: Description of the Earth system model of intermediate complexity LOVECLIM version 1.2, Geosci. Model Dev., 3, 603-633, doi:10.5194/gmd-3-603-2010, 2010.

Gordon, A. L.: Seasonality of Southern Ocean sea ice, J. Geophys. Res., 86, 4193-4197, 1981.

Gordon, A. L.: Two stable modes of Southern Ocean winter stratification, in: Deep convection and deep water formation in the oceans, edited by: Chu, P. C. and Gascard, J. C., Elsevier Oceanography series 57, Elsevier, Amsterdam, Netherlands, 1735, 1991.

Hazeleger, W., Severijns, C., Semmler, T., Ştefănescu, S., Yang, S., Wang, X., Wyser, K., Dutra, E., Baldasano, J. M., Bintanja, R., Bougeault, P., Caballero, R., Ekman, A.M. L., Christensen, J. H., van den Hurk, B., Jimenez, P., Jones, C., Kållberg, P., Koenigk, T., McGrath, R., Miranda, P., Van Noije, T., Palmer, T., Parodi, J. A., Schmith, T., Selten, F., Storelvmo, T., Sterl, A., Tapamo, H., Vancoppenolle, M., Viterbo, P., and Willén, U.: EC-Earth: A seamless Earth-system prediction approach in action, Bull. Am.
Meteorol. Soc., 91, 1357-1363, doi:10.1175/2010BAMS2877.1 , 2010.

Holland, P. R. and Kwok, R.: Wind-driven trends in Antarctic sea-ice drift, Nat. Geosci., 5, 872-875, doi:10.1038/NGEO1627, 2012.

Holland, M. and Raphael, M.: Twentieth century simulation of the southern hemisphere climate in coupled models, Part II: sea ice conditions and variability, Clim. Dynam., 26, 229-245, doi:10.1007/s00382-005-0087-3, 2006.

Jacobs, S. S., Giulivi, C. F., and Mele, P. A.: Freshening of the Ross Sea during the late 20th century, Science, 297, 386-389, doi:10.1126/science.1069574, 2002.

Kay, J. E., Raeder, J. E., Gettelman, A., and Anderson, J.: The boundary layer response to recent Arctic sea ice loss and implications for high-latitude climate feedbacks, J. Climate, 24, 428447, doi:10.1175/2010JCLI3651.1, 2011.

Kirkman IV, C. H. and Bitz, C. M.: The Effect of the Sea Ice Freshwater Flux on Southern Ocean Temperatures in CCSM3: DeepOcean Warming and Delayed Surface Warming, J. Climate, 24, 2224-2237, doi:10.1175/2010JCLI3625.1, 2010.

Kistler, R., Collins, W., Saha, S., White, G., Woollen, J., Kalnay, E., Chelliah, M., Ebisuzaki, W., Kanamitsu, M., Kousky, V., van den Dool, H., Jenne, R., and Fiorino, M.: The NCEP-NCAR 50-Year Reanalysis: Monthly Means CD-ROM and Documentation, Bull. Am. Meteorol. Soc., 82, 247-267, doi:10.1175/15200477(2001)082<0247:TNNYRM>2.3.CO;2, 2001.

Lefebvre, W. and Goosse, H.: Analysis of the projected regional sea-ice changes in the Southern Ocean during the 21 st century, Clim. Dynam., 30, 59-76, doi:10.1007/s00382-007-0273-6, 2008a.

Lefebvre, W. and Goosse, H.: An analysis of the atmospheric processes driving the large-scale winter sea-ice variability in the Southern Ocean, J. Geophys. Res., 113, C02004, doi:10.1029/2006JC004032, 2008b.

Lefebvre, W., Goosse, H., Timmermann, R., and Fichefet, T.: Influence of the Southern Annular Mode on the sea-ice-ocean system, J. Geophys. Res., 109, C090005, doi:10.1029/2004JC002403, 2004.

Lenderink, G. and Haarsma, R. J.: Variability and Multiple Equilibria of the Thermohaline Circulation Associated with Deep-Water Formation, J. Phys. Oceanogr., 24, 1480-1493, doi:10.1175/1520-0485(1994)024<1480:VAMEOT>2.0.CO;2, 1994.

Lenderink, G. and Haarsma, R. J.: Modeling convective transitions in the presence of sea ice, J. Phys. Oceanogr., 26, 1448-1467, doi:10.1175/1520-0485, 1996.

Liu, J. and Curry, J. A.: Accelerated warming of the Southern Ocean and its impacts on the hydrological cycle and sea ice, Search Results, Proc. Natl. Acad. Sci., 107, 14987-14992, doi:10.1073/pnas.1003336107, 2010.

Liu, J., Curry, J. A., and Martinson, D. G.: Interpretation of recent Antarctic sea ice variability, Geophys. Res. Lett., 31, L02205, doi:10.1029/2003GL018732, 2004.

Mahlstein, I., Gent, P. R., and Solomon, S.: Historical Antarctic mean sea ice area, sea ice trends, and winds in CMIP5 simulations, J. Geophys. Res., 118, 5105-5110, doi:10.1002/jgrd.50443, 2013.

Marshall, G. J.: Trends in the Southern Annular Mode from observations and reanalyses, J. Climate, 16, 4134-4143, 
doi:10.1175/1520-0442(2003)016<4121:AGEOMP>2.0.CO;2, 2003.

Marsland, S. J. and Wolff, J. O.: On the sensitivity of Southern Ocean sea ice to the surface freshwater flux: A model study, J. Geophys. Res., 106, 2723-2741, doi:10.1029/2000JC900086, 2001.

Martin, T., Park, W., and Latif, M.: Multi-centennial variability controlled by Southern Ocean convection in the Kiel Climate Model, Clim. Dynam., 40, 2005-2022, doi:10.1007/s00382-012-1586-7, 2013.

Martinson, D. G.: Evolution of the Southern Ocean winter mixed layer and sea ice: open ocean deepwater formation and ventilation, J. Geophys. Res., 95, 11641-11654, doi:10.1029/JC095iC07p11641, 1990.

Martinson, D. G., Killworth, P. D., and Gordon, A. L.: A convective model for the Weddell Polynya. J. Phys. Oceanogr., 11, 466-488, 1981.

Massonnet, F., Fichefet, T., Goosse, H., Vancoppenolle, M., Mathiot, P., and König Beatty, C.: On the influence of model physics on simulations of Arctic and Antarctic sea ice, The Cryosphere, 5, 687-699, doi:10.5194/tc-5-687-2011, 2011.

Meier, W. N., Gallaher, D., and Campbell, G. G.: New estimates of Arctic and Antarctic sea ice extent during September 1964 from recovered Nimbus I satellite imagery, The Cryosphere, 7, 699705, doi:10.5194/tc-7-699-2013, 2013.

Mikolajewicz, U. and Maier-Reimer, E.: Internal secular variability in an ocean general circulation model, Clim. Dynam., 4, 145156, 1990.

Mikolajewicz, U. and Maier-Reimer, E.: Mixed boundary conditions in ocean general circulation models and their influence on the stability of the model's conveyor belt, J. Geophys. Res., 99, 22633-22644, doi:10.1029/94JC01989, 1994.

Nguyen, A. T., Menemenlis, D., and Kwok, R.: Improved modeling of the Arctic halocline with a subgrid-scale brine rejection parameterization, J. Geophys. Res., 114, C11014, doi:10.1029/2008JC005121, 2009.

Opsteegh, J. D., Haarsma, R. J., Selten, F. M., and Kattenberg, A.: ECBilt: A dynamic alternative to mixed boundary conditions in ocean models, Tellus, 50A, 348-367, doi:10.1034/j.16000870.1998.t01-1-00007.x, 1998.

Orsi, A. H. and Wiederwohl, C. L.: A recount of Ross Sea waters, Deep-Sea Res. Pt. II, 56, 778-795, doi:10.1016/j.dsr2.2008.10.033, 2009.

Parkinson, C. L. and Cavalieri, D. J.: Antarctic sea ice variability and trends, 1979-2010, The Cryosphere, 6, 871-880, doi:10.5194/tc-6-871-2012, 2012.

Polvani, L. M. and Smith, K. L.: Can natural variability explain observed Antarctic sea ice trends? New modeling evidence from CMIP5, Geophys. Res Lett., 40, 3195-3199, doi:10.1002/grl.50578, 2013.

Qu, X. and Hall, A.: Assessing snow albedo feedback in simulated climate change, J. Climate, 19, 2617-2630, doi:10.1175/JCLI4186.1, 2006.
Santoso, A. and England, M.: Antarctic bottom water variability in a coupled climate model, J. Phys. Oceanogr., 38, 1870-1893, doi:10.1175/2008JPO3741.1, 2008.

Sen Gupta, A., Santoso, A., Taschetto, A. S., Ummenhofer, C. C., Trevena, J., and England, M. H.: Projected changes to the Southern Hemisphere ocean and sea ice in the IPCC AR4 climate models, J. Climate, 22, 3047-3078, doi:10.1175/2008JCLI2827.1, 2009.

Sen Gupta, A., Muir, L. C., Brown, J. N., Phipps, S. J., Durack, P. J., Monselesan, D., and Wijffels, S. E.: Climate drift in the CMIP3 Models, J. Climate, 25, 4621-4640, doi:10.1175/JCLID-11-00312.1, 2012.

Simpkins, G. R., Ciasto, L. M., Thompson, D. W. J., and England, M. H.: Seasonal Relationships between Large-Scale Climate Variability and Antarctic Sea Ice Concentration, J. Climate, 25, 5451-5469, doi:10.1175/JCLI-D-11-00367.1, 2012.

Stössel, A. and Kim, S.-J.: An interannual Antarctic sea-ice-ocean mode, Geophys. Res. Lett., 25, 1007-1010, 1998.

Stössel, A. and Kim, S.-J.: Decadal deep-water variability in the subtropical Atlantic and convection in the Weddell Sea, J. Geophys. Res. Oceans, 106, 22425-22440, doi:10.1029/2000JC000335, 2001.

Swart, N. C. and Fyfe, J. C.: The influence of recent Antarctic ice-sheet retreat on simulated sea-ice area trends, Geophys. Res. Lett., 40, 1-5, doi:10.1002/grl.50820, 2013.

Swingedouw, D., Fichefet, T., Huybrechts, P., Goosse, H., Driesschaert, E., and Loutre, M. F.: Antarctic ice-sheet melting provides negative feedbacks on future climate warming, Geophys. Res. Lett., 35, L17705, doi:10.1029/2008GL034410, 2008.

Timmermann, R., Hellmer, H. H., and Beckmann, A.: Simulations of ice-ocean dynamics in the Weddell Sea 2, Interannual variability 1985-1993, J. Geophys. Res., 107, 11-1-11-9, doi:10.1029/2000JC000742, 2002.

Turner, J., Bracegirdle, T. J., Phillips, T., Marshall, G. J., and Hosking, J. S.: An Initial Assessment of Antarctic Sea Ice Extent in the CMIP5 Models, J. Climate, 26, 1473-1484, doi:10.1175/JCLID-12-00068.1, 2013.

van Leeuwen, P. J.: Particle filtering in geophysical systems, Mon. Weather Rev., 137, 4089-4114, 2009.

Yuan, X. and Li, C.: Climate modes in southern high latitudes and their impact on Antarctic sea ice, J. Geophys. Res., 113, C06S91, doi:10.1029/2006JC004067, 2008.

Zhang, J.: Increasing Antarctic sea ice under warming atmospheric and oceanic conditions, J. Climate, 20, 2515-2529, doi:10.1175/JCLI4136.1, 2007.

Zunz, V., Goosse, H., and Massonnet, F.: How does internal variability influence the ability of CMIP5 models to reproduce the recent trend in Southern Ocean sea ice extent?, The Cryosphere, 7, 451-468, doi:10.5194/tc-7-451-2013, 2013. 